\title{
La red de las comisiones extraparlamentarias (1910- 2000): auge $y$ declive de una expresión institucional del neocorporativismo helvético ${ }^{1}$
}

\author{
Frédéric Rebmann ${ }^{2}$-Instituto de historia económica y social-Universidad de Lausana ${ }^{3}$
}

\begin{abstract}
Resumen
Las comisiones extraparlamentarias son órganos administrativos que asumen tareas consultivas o ejecutivas para el Gobierno, pero que están compuestas, esencialmente, por personas ajenas a la Administración Federal. En este sentido, las comisiones están en tensión, entre una lógica de evaluación de competencias y una lógica de representación. A partir de un análisis estructural de redes, hemos podido distinguir estas dos lógicas poniendo de manifiesto, en particular, las especificidades de la segunda: así pues, hemos analizado, de acuerdo con un enfoque diacrónico que abarca cinco fechas del siglo XX (los años 1910, 1937, 1957, 1980 y 2000), la evolución de la morfología de los vínculos entre comisiones y actores a partir de los cuales se operan procesos de coordinación, de concesión y de negociación política. Nuestros estudios han mostrado que estos vínculos de "concordancia" se intensifican de forma continua entre 1910 y 1980, con una aceleración marcada a partir del fin de la Segunda Guerra Mundial. Estos vínculos han sido desarrollados básicamente por las diferentes asociaciones de intereses y atañen casi exclusivamente a las políticas económicas y sociales. Es así como las CEP aparecen por esa fecha como una de las principales instituciones neocorporativistas de concordancia. No obstante, esta evolución se invierte considerablemente entre 1980 y 2000, con una disminución importante de este tipo de vínculos, lo cual cuestiona la lógica de coordinación de las comisiones. La explicación la hallamos principalmente en los factores siguientes: el proceso de reforma del sistema comisionista que se inicia en los años 70, el proceso de internacionalización que afecta a Suiza desde los años 80 , y por último, un cambio de preferencias y de repertorio de acción de un cierto número de asociaciones económicas y sociales, que se alejan progresivamente de los mecanismos de cooperación transversal característicos de los regímenes neocorporativistas. No obstante, a pesar de esta evolución, un núcleo de concordancia se mantiene, sobre una base más limitada, en las asociaciones de intereses "tradicionales" respecto a algunas políticas económicas y sociales.
\end{abstract}

Palabras clave: Suiza - Comisiones extraparlamentarias - Asociaciones de intereses Evaluación de competencias - Representación.

\begin{abstract}
Extra-parliamentary commissions (EPC) are organs that assume consultative or executive tasks on behalf of the government and the administration but are essentially composed of persons who are not civil servants. As a consequence, they express the tension between the logic of expertise and the logic of representation. Thanks to a structural network analysis, we distinguished these two logics and highlighted the specificities of the second: according to a diachronic approach based on five years of the 20th century (1910, 1937, 1957, 1980, and 2000), we analyzed the specific evolution of the ties between commissions and between members that are parts of a log-rolling and

\footnotetext{
1 Traducción realizada por Marta Cases Bobadilla

2 El autor agradece sus comentarios instructivos sobre las versiones anteriores del presente artículo a Claire Lemercier, Thomas David, André Mach y a dos comentaristas anónimos.

${ }^{3}$ Para escribir a Frédéric Rebmann: Frederic.Rebmann@unil.ch
} 
bargaining process. Our research showed that these kinds of ties became denser from 1910 to 1980, with acceleration beginning with the Second World War. These coordinative ties linked social and economic policies together and were developed, essentially, by the interests associations. As a consequence, the EPCs largely appear to be one of the main neocorporatist institutions during this period. However, this evolution was reversed between 1980 and 2000 with the important diminution of these coordinative ties, which called into question the neocorporatist role of the EPCs. Three main factors can be discussed to explain this evolution: the process reform of the EPC system that started in the 1970s, the globalization process that began in the 1980s, and, finally, a change in the strategies of the interest associations that progressively neglected cooperatives and neocorporatist mechanisms. However, despite this general evolution, a coordinative core persisted between some "traditional" interest associations.

Key words: Switzerland - Extraparliamentary commissions - Interests Associations Expertise - Representation.

\section{Introducción}

Las comisiones extraparlamentarias (CEP) son instancias administrativas que asumen tareas consultivas o ejecutivas para el Gobierno, y que están básicamente compuestas por personas ajenas a la Administración Federal. En este sentido, en general se clasifican en la categoría de las instancias administrativas "paraestatales" o "militantes", hallándose de esta manera en el cruce de las lógicas de evaluación de competencias y de representación: efectivamente, en calidad de comités de evaluación de competencias, las CEP representan para las autoridades federales, cuyo aparato administrativo está poco desarrollado, un vector de adquisición de competencias y de capacidad de análisis a bajo costo. Sin embargo, al estar parcialmente compuestas por representantes de organizaciones privadas, las CEP encarnan también una de las principales instancias neocorporativistas del sistema político suizo, ya que permiten a los principales grupos de intereses gozar de una representación en la esfera administrativa, y que se respeten sus intereses durante la fase pre-parlamentaria del proceso de decisión (Germann y Frutiger 1978; Germann 1981: 190-191; Germann 1987; Rüegg 1992: 112; Sägesser 2007: $514)$.

Analizar el papel y la función de las CEP dentro del sistema político suizo implica, por lo tanto, colocar en el centro de nuestro análisis esta tensión entre lógicas de evaluación de competencias y de representación - tal y como Chatriot y Lemercier lo han hecho con Francia (véase en particular Chatriot 2002; Chatriot y Lemercier 2002 y 2008) - y problematizar su impacto respectivo sobre el sistema democrático. ¿Representan las CEP instancias de asesoría política supeditadas a las autoridades elegidas por vía democrática, o bien, al contrario, influyen sobre la voluntad política prescindiendo de las opciones democráticas fundamentales? Dicho de otra manera, focalizándonos básicamente en la segunda lógica, más allá de las instituciones usuales de la democracia 
REDES- Revista hispana para el análisis de redes sociales

Vol.21,\#10, Diciembre 2011

http://revista-redes.rediris.es

parlamentaria directa o semidirecta que caracterizan el sistema suizo, ¿en qué medida representa el sistema comisionista una institución de "democracia social" (Chatriot 2002: 3) que otorga a las distintas legitimidades asociativas - patronales y sindicales en primer lugar - la posibilidad de influir sobre la definición de las políticas públicas?

Si el carácter neocorporativista de las CEP se ha interpretado y destacado a menudo insistiendo en el hecho de que los compromisos políticos precoces se establecen entre las principales asociaciones de intereses, de acuerdo con los mecanismos de "concordancia" (para la definición del término, véase Morandi 2005) en los que la búsqueda de acuerdos amistosos prevalece sobre el principio de mayoría (Rüegg 1992) - nunca se ha demostrado al nivel del conjunto del sistema. Más allá de algunas aclaraciones puntuales que se limitan a algunas comisiones (en particular Pavillon 2001), poco sabemos acerca de la estructura y de la envergadura global de los mecanismos neocorporativistas de concordancia en el sistema comisionista, así como de la evolución de éstos a lo largo del siglo XX. Los actores que están en el origen de estas prácticas, y las políticas públicas que están implicadas, siguen sin estar claramente delimitados. De manera global, existen aún muchas lagunas en la historiografía relativa a las comisiones extraparlamentarias, a pesar de algunos estudios sobre los años 70 (en particular Germann 1981, Frutiger 1983 y Germann et alter 1985).

Recurrir a un análisis estructural de red es un enfoque original; con ello, el objetivo de la presente contribución es subsanar estas numerosas lagunas, delimitando en particular las zonas o los núcleos dentro de los cuales se establecen mecanismos de concordancia. En efecto, tenemos la intención de centrar nuestro análisis en los vínculos que se establecen dentro del sistema comisionista, entre las comisiones, pero también entre sus miembros, y que constituyen la estructura de intercambio dentro de la cual toman forma estos mecanismos. Al centrarnos en cinco hitos cronológicos (1910, 1937, 1957, 1980 y 2000), llevamos a cabo nuestro análisis sobre una base diacrónica, reconstituyendo la evolución de la red a lo largo del siglo XX. De esta manera, se trata de ir más allá de los enfoques estrictamente sincrónicos o de los estudios de caso sectoriales que son característicos a la hora de tratar este tema, desarrollando un análisis sistemático de la red de las comisiones extraparlamentarias en su globalidad. Tal y como mencionan Knoke y Kuklinski (1993: 9-10),

"Network analysis, by emphasizing relations that connect the social positions within a system, offers a powerful brush for painting a systematic picture of global social structures and their components". 
REDES- Revista hispana para el análisis de redes sociales

Vol.21,\#10, Diciembre 2011

http://revista-redes.rediris.es

Así pues, el análisis de red nos debe permitir definir la forma y el desarrollo de las estructuras de concordancia, las comisiones implicadas por estas prácticas, y los actores que participan en ellas.

\subsection{La importancia de las comisiones extraparlamentarias dentro del proceso de decisión: estado de la cuestión}

Durante la mayor parte del siglo XX, las CEP representan una institución opaca y mal conocida del sistema político suizo. Tal y como mencionan Germann et alter (1985: 2),

"la administración de milicia, por muy importante que sea, ha estado rodeada durante mucho tiempo por un halo de misterio, sin suscitar ni un debate público, ni investigaciones sistemáticas".

En efecto, hasta los años 70, la creación de una comisión dependía muchas veces de la discreción de las distintas unidades administrativas (Departamentos, Oficinas, etc.) sin que éstas informaran necesariamente a las autoridades políticas (OPCA 1994: 6, 35). Por consiguiente, el número total de comisiones, así como su composición, no se conoce con precisión: sólo una lista parcial de las comisiones se publicaba en el Anuario Federal Oficial. Por otra parte, su estatuto y sus prerrogativas eran considerablemente opacos e informales, al igual que las actividades de la Delegación Económica Permanente, órgano de negociación económica creado en 1939 por el Consejo Federal y compuesto, además de los funcionarios federales antepuestos a las negociaciones económicas, por representantes de las principales asociaciones de intereses helvéticas. Este órgano consultivo, sin fundamento legal, establecido sobre la base de una decisión no publicada del Gobierno, y de cuyas sesiones no se tomaban actas, desempeñó sin embargo un papel muy importante en los procesos de decisión relativos a las relaciones económicas exteriores de Suiza durante ese periodo (OPCA 1994). En este sentido, Hug (1988: 222) habla de una delegación informal, flexible, oligárquica, dotada de un carácter clandestino.

Aunque el conjunto de las comisiones no comparte todas estas características, esta situación contribuye, a partir de los años 50 , a suscitar un debate cada vez más presente sobre el papel de las CEP dentro del proceso de decisión federal, y del lugar que ocupan en él las asociaciones de intereses (OPCA 1994): 
"la primera función del Parlamento es legislar. Mas, hoy en día, los miembros de esta venerable institución ejercen mucha menos influencia sobre el contenido de los actos legislativos que los órganos o autoridades que los han elaborado a lo largo del procedimiento extraparlamentario, es decir la administración, las comisiones de expertos, las asociaciones y organizaciones económicas." (Feuille fédérale (FF) 1978 II: 1184$)^{4}$.

Neidhart (1970:185ss.) es uno de los primeros científicos en cuestionar el papel y la función de las CEP: según él, debido a la presión plebiscitaria ${ }^{5}$ constante ejercida sobre el sistema político suizo, éstas se convirtieron en poco tiempo en el lugar de integración, en el marco de los procedimientos consultivos pre-parlamentarios, de las principales fuerzas económicas y sociales. Así pues, calcula que los dos tercios de los puestos en las comisiones estarían ocupados por las asociaciones profesionales, y el otro tercio correspondería a los funcionarios federales o cantonales, o a los representantes universitarios.

En el aumento de estas interpelaciones hemos de buscar el origen, a partir del principio de los años 70, del lanzamiento de un proceso de reforma del sistema comisionista cuyas dos principales expresiones son las Directivas vinculadas con el procedimiento preliminar en materia de legislación del 6 de mayo 1970 y las Directivas relativas a la institución y al modo de trabajo de las comisiones extraparlamentarias así como la vigilancia que se debe ejercer sobre ellas del 3 de julio 1974. Es así como, por primera vez, estos dos reglamentos permiten normalizar la creación, el estatuto y el funcionamiento de las comisiones, y contribuyen, en cierta medida, a la transparencia del conjunto del sistema (OPCA 1994: 6, 35).

Estas reformas abren el camino a investigadores como Germann y sus colaboradores, cuyos estudios se inscriben en esta línea, y que analizan el funcionamiento y la composición de las comisiones extraparlamentarias, en particular a partir del registro del conjunto de las comisiones correspondiente al año 1978 (Germann 1981 y Germann et alter 1985). Para dicho año, enumeran más de 370 comisiones extraparlamentarias compuestas por más de 3800 expertos para un total de unos 5000 puestos. A modo de comparación, mencionemos que la administración central (sin correos - PTT - ni la red de ferrocarriles federales) tan sólo cuenta, en el mismo periodo, con 32000 funcionarios federales. Tal y como demuestran estos estudios, el sistema comisionista está compuesto

\footnotetext{
${ }^{4}$ Respecto al tema de la reforma del Parlamento que se lleva a cabo en paralelo, véase Pilotti et alter (2010).

${ }^{5}$ El referéndum facultativo popular es un procedimiento constitucional que permite a los ciudadanos reclamar que una ley votada por el Parlamento se someta a un voto popular, siempre y cuando se hayan conseguido 50.000 firmas. En la práctica, este instrumento, que requiere la movilización de recursos económicos y una organización importantes, lo utilizan sobre todo las principales asociaciones de intereses o los partidos políticos. Tal y como menciona Degen (2010), "El referéndum se considera muy a menudo como un freno que conduce a compromisos e imposibilita una política de mayoría. Para evitar esto, todas las fuerzas susceptibles de lanzarlo con éxito deben estar lo más integradas posible a los procesos de decisión [...]. Es así como la fase preparlamentaria del trabajo legislativo cobró una dimensión preponderante".
} 
REDES- Revista hispana para el análisis de redes sociales

Vol.21,\#10, Diciembre 2011

http://revista-redes.rediris.es

por varios tipos de CEP. En general, se distinguen dos categorías principales: las comisiones consultivas, que son las más numerosas y se encargan exclusivamente de las tareas preparatorias; y las comisiones de decisión, que representan alrededor del $20 \%$ de la totalidad de las CEP y, que, a diferencia de las mencionadas anteriormente, están habilitadas para tomar decisiones (OPCA 1994: 30; Germann 2005). Estos dos tipos de comisiones asumen múltiples tareas, casi todas relacionadas con todos los campos de la actividad estatal al nivel federal. En general, las comisiones consultivas están encargadas de proporcionar a la administración una evaluación e información; también participan con frecuencia en las tareas preparatorias de pre-proyectos de leyes o de ordenanzas que luego se someten al Parlamento. En cuanto a las comisiones de decisión, éstas asumen la vigilancia, el control e incluso la aplicación de algunas políticas públicas, y disponen, bajo este concepto, de su propio secretariado. Es preciso mencionar una última categoría de CEP, las comisiones de expertos ad hoc, convocadas de manera puntual y por tiempo limitado, para tratar un asunto en particular. No obstante, no existe ningún repertorio sistemático de este tipo de comisiones.

La obra de Germann permite, 10 años después de los números enunciados por Neidhart (1970), retomar el debate sobre la cuestión de la composición de las CEP, proporcionando, esta vez, datos sistemáticos. Germann y sus colaboradores insisten sobre el hecho de que los intereses organizados no son, ni de lejos, mayoritarios en el sistema, dado que se calcula que la parte de mandatos que ejercen éstos últimos es de menos del 20 \% (Germann 1981: 52ss.; Frutiger 1983: 16ss.). Por otra parte, parece que, a pesar de la dinámica de reforma de los años 70, la composición de las comisiones ha permanecido poco reglamentada. El uso del principio de cooptación está muy extendido, ya que los presidentes o algunos miembros pueden ejercer una influencia cuando se trata de conceder los puestos (Germann 1981: 194; 1996: 96-97). Es más, las autoridades federales no designan a todos los miembros de las comisiones; algunos, al contrario, acceden a los puestos de las comisiones según el principio del "mandato institucional" (Germann et alter 1985: 91). Frente a este tipo de situación, la administración se contenta, en efecto, con invitar a una organización pública o privada, y ésta última designa libremente a la persona encargada de representarla en el sistema comisionista. Las asociaciones de intereses helvéticas adoptan frecuentemente esta práctica, que desempeña, tal y como veremos más adelante, un papel central en la constitución de redes de concordancia. 
Desde entonces, no se ha llevado a cabo ningún análisis del sistema comisionista, con lo que sabemos poco acerca de su reciente evolución así como del periodo anterior a los años 70 (véase no obstante Rebmann y Mach 2012 para una presentación sucinta de la evolución a lo largo de los últimos 30 años). Además, los pocos estudios que existen sólo han considerado la composición de las comisiones a partir del censo de la parte de puestos que tiene cada grupo económico o social. Este enfoque es interesante y necesario, pero no suficiente. En efecto, es demasiado estático, y no puede sacar a la luz las lógicas de negociación y de concertación transversales, típicas de los regímenes neocorporativistas. Dicho de otra manera, la mera presencia de los representantes de los intereses particulares no es suficiente para explicar la emergencia de los mecanismos neocorporativistas de concordancia; éstos también dependen de la existencia de estructuras o de redes institucionales de coordinación. Esta red se constituye básicamente a partir de la acumulación de mandatos por un número limitado de actores, a los que se llama los "pluriexpertos" o los pluriempleados. Comúnmente, se considera que ocupan una posición estratégica dentro del sistema (Germann 1981: 104ss.), y que disponen de un poder similar al del "marginal-secante" tal y como lo definen Crozier y Friedberg (1977: 73). En efecto, éstos, que a veces acumulan varias decenas de mandatos en diversas comisiones, asumen cargos de dirección, de control, de coordinación y de intermediaridad, y se hallan pues en el centro de los procesos de logrolling y de bargaining. Las concesiones acordadas en una comisión las compensan las ventajas obtenidas en cada uno de estos dos procesos (Germann y Frutiger 1978: 107). Estos mecanismos se sitúan en el centro de un funcionamiento neocorporativista de concordancia y los asumen, básicamente, las principales asociaciones centrales. En este sentido, el análisis de red representa un instrumento particularmente adaptado para comprender cuáles son las especificidades de esta red de coordinación, y cómo ha evolucionado a lo largo del siglo XX.

\subsection{Datos y método}

Para analizar la evolución de la red de las CEP, hemos seleccionado cinco hitos cronológicos repartidos a lo largo del siglo XX (1910,1937, 1957, 1980 y 2000) y hemos compilado el conjunto de las comisiones permanentes de estas fechas ${ }^{6}$. La elección de no tener en cuenta las comisiones permanentes tiene su explicación en la ausencia de un

\footnotetext{
${ }^{6}$ Un análisis de la dinámica comisionista en el siglo XX que abarca cinco hitos cronológicos tiene un carácter arbitrario. No obstante, estos cinco hitos, separados entre ellos sí por un intervalo de veinte años, permiten considerar, en términos de periodización, las grandes etapas económicas, sociales y políticas de la historia suiza: una fecha anterior a la Primera Guerra Mundial, una durante el periodo de entreguerras, una durante el periodo de crecimiento de los Treinta Gloriosos, una al final de este periodo de crecimiento, y una en el cambio del siglo XX al siglo XXI. Obsérvese, por otro lado, que el presente estudio se inscribe en el marco del proyecto intitulado titulado??? "las élites suizas en el siglo XX. ¿Un proceso de diferenciación inacabado?" (véase www.unil.ch/iepi/page54315.html). La elección de estas cinco fechas corresponde pues, también, a líneas de investigación más generales definidas para este proyecto.
} 
REDES- Revista hispana para el análisis de redes sociales

Vol.21,\#10, Diciembre 2011

http://revista-redes.rediris.es

repertorio sistemático de las comisiones ad hoc, y en el hecho de que las comisiones permanentes son CEP activas a largo plazo, con lo cual un análisis diacrónico parece más adaptado. Tal y como está indicado en el cuadro 1, las comisiones extraparlamentarias dependen de uno de los siete Departamentos Federales ${ }^{7}$. También hemos incluido en nuestros datos las comisiones del Banco Nacional Suizo (BNS), el consejo del banco, la comisión de control y el comité del banco; aunque no forman parte de las comisiones extraparlamentarias de manera formal, constituyen órganos "de milicia" compuestos por personas ajenas a la administración. Un análisis de las redes de coordinación neocorporativistas debe tener en cuenta la política monetaria, cuya importancia macroeconómica es bien conocida (Mach 2006b: 236).

\begin{tabular}{|l|c|c|c|c|c|}
\hline & $\mathbf{1 9 1 0}$ & $\mathbf{1 9 3 7}$ & $\mathbf{1 9 5 7}$ & $\mathbf{1 9 8 0}$ & $\mathbf{2 0 0 0}$ \\
\hline Banque nationale suisse & $5 \%$ & $4 \%$ & $1 \%$ & $1 \%$ & $2 \%$ \\
\hline Département fédéral de justice et police & $0 \%$ & $0 \%$ & $2 \%$ & $4 \%$ & $8 \%$ \\
\hline Département fédéral de l'intérieur & $15 \%$ & $30 \%$ & $25 \%$ & $29 \%$ & $39 \%$ \\
\hline Département fédéral des finances & $2 \%$ & $15 \%$ & $11 \%$ & $8 \%$ & $7 \%$ \\
\hline Département fédéral de l'économie & $7 \%$ & $11 \%$ & $29 \%$ & $23 \%$ & $23 \%$ \\
\hline Département fédéral des affaires étrangères & $0 \%$ & $0 \%$ & $6 \%$ & $7 \%$ & $5 \%$ \\
\hline Département fédéral des transports et de l'énergie & $58 \%$ & $27 \%$ & $14 \%$ & $17 \%$ & $16 \%$ \\
\hline Département militaire fédéral & $14 \%$ & $13 \%$ & $12 \%$ & $11 \%$ & $3 \%$ \\
\hline Nombre de commissions & $\mathbf{5 9}$ & $\mathbf{7 1}$ & $\mathbf{2 2 6}$ & $\mathbf{3 0 0}$ & $\mathbf{1 9 7}$ \\
\hline & & & & & \\
\hline Nombre de personnes & 271 & 503 & 1750 & 2781 & 1809 \\
\hline Nombre de mandats & 297 & 613 & 2566 & 3791 & 2121 \\
\hline
\end{tabular}

Cuadro 1. Número de comisiones por año y por Departamento, número de personas, número de mandatos Fuentes: Base de datos ElitesSuisse.

Nota: Hemos utilizado las denominaciones más frecuentes para designar los distintos Departamentos. Sin embargo, es obvio que el nombre de los Departamentos, así como sus atribuciones, han podido cambiar entre 1910 y 2000.

Varias fuentes nos han permitido recopilar los datos pertinentes para nuestro análisis: los Anuarios Federales, que censan una parte importante de las comisiones extraparlamentarias, son la principal. No obstante, esta fuente es muy incompleta para el periodo comprendido entre los años 40 y 80 (Arnold 1969). Hemos tenido pues que recurrir a un examen minucioso de los fondos documentales relativos a las comisiones extraparlamentarias dentro de los Archivos Federales Suizos para completar nuestras fuentes. Podemos considerar que los datos de nuestras cinco fechas son exhaustivos.

Tal y como se puede apreciar a partir del cuadro 1, el sistema comisionista se extiende durante la mayor parte del siglo XX. Sólo entre 1980 y 2000 disminuyen los efectivos. Por otra parte, su centro de gravedad evoluciona entre 1910 y 2000 . Durante el periodo que nos ocupa, tres Departamentos concentran más de los dos tercios de las comisiones: se trata del Departamento de Transportes y de Energía, que en general también acoge las comisiones sobre medioambiente y comunicación; del Departamento de Interior, que suele tener a su cargo las políticas científicas, culturales y de los seguros sociales desde los años $50^{8} ;$ y por último, del Departamento de Economía, encargado de todas las

\footnotetext{
${ }^{7}$ Los Departamentos Federales representan los ministerios del Gobierno. Son siete y se caracterizan por una gran estabilidad, dado que su número no ha cambiado desde la creación del Estado federal en 1848.

${ }^{8}$ La Agencia Federal de los Seguros Sociales, que dependía en un principio del Departamento de Economía, y que controlaba todas las comisiones encargadas de este tema desde 1913, fue transferida al Departamento de Interior en 1954 (véase el Anuario Federal, diferentes años).
} 
REDES- Revista hispana para el análisis de redes sociales

Vol.21,\#10, Diciembre 2011

http://revista-redes.rediris.es

cuestiones relativas a la política económica interior, y a las políticas comercial, laboral y agrícola. Pero, entre 1937 y 1957, se produce un cambio de efectivos del primer Departamento hacia los otros dos, con lo cual desde entonces los Departamentos de Economía y de Interior concentran más de la mitad del conjunto de las comisiones. Las cuestiones económicas y las cuestiones relativas a los seguros sociales son los principales temas en los que hallamos el origen del aumento del número de CEP, y están en el centro de los mecanismos de log-rolling.

Partiendo de la base de un análisis estructural de la red (Lemercier 2005) que se centra en la población total de las CEP y de sus miembros, y realizado a partir de los programas Pajek (de Nooy et alter 2005) y Ucinet (Borgatti et alter 2002), nuestro enfoque consiste en analizar la morfología de los vínculos formados a partir del fenómeno de acumulación de los mandatos, es decir, cuando dos comisiones tienen al menos un miembro en común. El valor del vínculo es proporcional al número de miembros que dos comisiones tienen en común. Varios autores insisten en el hecho de que existe una íntima relación entre la fuerza o la densidad de estos vínculos y el establecimiento de dinámicas sociales como la colaboración o la coordinación (véase de Nooy et alter 2005: 61 para una descripción general, o Mizruchi 1992 y Windolf 2007 para una ejemplificación con las redes de empresas). Dicho de otra manera, es dentro de los grupos de comisiones cuyos vínculos son más densos donde los principios de coordinación y de log-rolling tienen más posibilidades de establecerse.

No obstante, la delimitación de las lógicas de log-rolling y de bargaining no se puede establecer únicamente a partir del análisis de los vínculos más cohesivos. En efecto, las dinámicas de negociación política tienden a poner en relación a actores cuyos intereses son diferentes, e incluso divergen, y que eventualmente tienen que ponerse de acuerdo respecto a algunas concesiones sobre temáticas políticas a cambio de un beneficio o de apoyo en otras temáticas. Se trata pues, en el marco de esta contribución, de distinguir dos tipos de vínculos entre las comisiones. Por una parte, los vínculos relacionados efectivamente con los mecanismos de negociación política, en los que están en juego intereses diversos sobre políticas diferentes que dependen, desde un punto de vista de red, de una lógica exogámica: existen miembros comunes entre comisiones que tratan temas diferentes. Por otra parte, en cuanto a los vínculos que se establecen respecto a temas similares y entre actores similares, no sorprende este tipo de vínculos si tenemos en cuenta la necesidad de intercambio de evaluación de competencias (lógica endogámica). Para distinguir estos dos mecanismos, hemos agrupado las diferentes comisiones por sector de actividad política, y los diferentes actores, en función del grupo social representado (ver el anexo 4). Luego hemos efectuado el cálculo de densidad que 
censa, para las lógicas exogámicas, el número de vínculos que se observan entre las comisiones que tratan dos temáticas diferentes respecto al nombre de vínculos posibles (número de vínculos/ $\mathrm{N}^{2}$ ) y para las lógicas endogámicas, el número de vínculos que se observan entre las comisiones que tratan un mismo tema respecto a los números de vínculos posibles (número de vínculos/( $\left.\mathrm{N}^{*}(\mathrm{~N}-1)\right)$ ). ${ }^{9}$.

Se ha analizado la densidad existente entre las comisiones a partir del conjunto de los vínculos censados. Al contrario, para los vínculos entre los actores, hemos hecho una selección antes de efectuar los cálculos de densidad. En efecto, éstos tienen que ver con la única red $2 m$-core (o $2 m$-slices), que sólo abarca los vínculos cuyo valor equivale a 2 o más (véase de Nooy et alter 2005: 109). Dicho de otra manera, un vínculo entre dos actores sólo se censa si las dos personas poseen un puesto al menos en dos comisiones distintas. En efecto, la red $2 m$-core permite prescindir de los vínculos entre dos personas siempre y cuando posean un puesto en la misma comisión. Estos vínculos "intracomisiones" no nos interesan en el marco de nuestro análisis, dado que éste se centra en los vínculos "inter-comisiones".

Los vínculos exogámicos, que constituyen el principal índice de mecanismos de coordinación de los diferentes intereses sociales respecto a las políticas públicas, se sitúan en el centro de nuestro análisis. Nos proponemos distinguir los actores que están en el origen de estos vínculos, así como las políticas implicadas en estos intercambios, sacando a la luz las continuidades y las rupturas que las atraviesan. No obstante, nuestro análisis de red no puede analizar la índole de los vínculos que se establecen. Dicho de otra manera, si podemos circunscribir las temáticas y los actores que se hallan en el centro de las dinámicas de log-rolling, no nos es posible conjeturar, a partir de una base cuantitativa, sobre la orientación de las relaciones de fuerza que unen a los actores implicados. La morfología de la red no habla por sí misma: un análisis cuantitativo no puede prescindir de un conocimiento del punto de origen y del terreno de las comisiones (véase Lemercier 2005). Las dinámicas de negociación política que conducen a la elaboración de políticas de concordancia no significan, en efecto, que el intercambio de favores entre las partes presentes sea una partida sin ganancia ni pérdida. Para determinar las razones que conducen a elegir la coordinación en lugar de otra forma de relación, así como la forma específica que adopta esta coordinación, es preciso completar nuestro análisis con un desarrollo cualitativo que permita entender de manera más

\footnotetext{
${ }^{9}$ Véase Windolf (2005) para un análisis similar de una red de empresas. Por otro lado, hemos sometido estos resultados a un análisis de la varianza (ANOVA) que permite apreciar el sentido que tienen. En efecto, estos tests ofrecen la posibilidad de evaluar en qué medida nuestros resultados difieren de una distribución al azar (en Ucinet, función « structural blockmodel » para las lógicas exogámicas y función « variable homophily » para las lógicas endogámicas). El número de permutaciones efectuado por estos tests es de 5000 (véase Hanneman y Riddle 2005).
} 
REDES- Revista hispana para el análisis de redes sociales

Vol.21,\#10, Diciembre 2011

http://revista-redes.rediris.es

precisa la manera en que se desarrollan estos vínculos y las relaciones de fuerza en el nivel social en que se manifiestan.

\section{Auge y declive de la red de las comisiones extraparlamentarias: un enfoque diacrónico}

Antes de centrarnos en las comisiones y los actores centrales de las dinámicas de logrolling, haremos una primera estimación de la evolución de las características de la red de las comisiones extraparlamentarias entre 1910 y 2000 . Tal y como indican los indicadores del cuadro 2 y del anexo 1 , que presentan respectivamente el nivel de inclusión y de fragmentación de la red de las CEP así como de su representación gráfica, podemos distinguir dos fases principales: una fase de crecimiento de las interconexiones entre 1910 y 1980 , durante la cual se acentúa la cohesión de la red, y una fase de declive de los vínculos entre 1980 y 2000 , durante la cual la red tiende a fragmentarse.

\begin{tabular}{|l|c|c|c|c|c|}
\hline & 1910 & 1937 & 1957 & 1980 & 2000 \\
\hline Commissions & & & & & \\
\hline Commissions isolées (en \%) & 49 & 13 & 8 & 5 & 36 \\
\hline Composante principale (en \% du nombre total de commissions) & 12 & 80 & 89 & 94 & 61 \\
\hline Degré moyen & 1 & 3 & 10 & 10 & 3 \\
\hline Acteurs & & & & & \\
\hline Acteurs faisant partie du réseau 2-core (en \%) & 4 & 9 & 16 & 13 & 6 \\
\hline
\end{tabular}

Cuadro 2. Tamaño y estructura de la red de las comisiones extraparlamentarias y de sus miembros Fuente: Base de datos ElitesSuisse.

En efecto, los cuatro indicadores movilizados en el cuadro 2 constatan que las CEP se ponen en relación entre ellas progresivamente entre 1910 et 1980: el porcentaje de comisiones aisladas - es decir las comisiones que no se relacionan con ninguna otra CEP a través de un miembro en común - disminuye de manera sustancial y constante entre 1910 y 1980 . Hoy en día, el $95 \%$ de las comisiones se relacionan como mínimo con otra CEP. El indicador siguiente, relativo al tamaño del componente principal, pone de manifiesto el mismo fenómeno: en general, una red está compuesta por varios subgrupos independientes y no relacionados entre sí, a los que llamaremos componentes. El componente principal representa, en nuestro caso, la subred de comisiones más extensa, que pone en relación una gran diversidad de comisiones. Mas, entre 1910 y 1980, éste se vuelve cada vez más inclusivo: si en 1910 representa un 12 $\%$ del conjunto de las comisiones, en 1980 pasa al $94 \%$. Así pues, se puede constituir una extensa red de intercambios dentro de un componente que abarca la casi totalidad de las comisiones. El grado medio, que corresponde al promedio de CEP con las que una comisión está relacionada, también permite sacar a la luz la importante densidad de los vínculos dentro de la red de las comisiones entre 1910, periodo durante el cual las CEP están conectadas de promedio con al menos otra comisión, y 1980, año en que este 
número supera las 10 comisiones. Sin embargo, cabe mencionar que la evolución de este índice puede depender, en parte, de la evolución del tamaño promedio de las CEP. Asimismo, la proporción de actores que forman parte de la subred $2 m$-core aumenta continuamente entre 1910 y 1957 . Es pues una red cada vez más cohesiva la que tiende a formarse entre 1910 et 1980, red dentro de la cual se pueden establecer los procesos de intercambios de conocimientos o de coordinación. No obstante, esta dinámica creciente se invierte considerablemente entre 1980 y 2000 : en esta fecha el $36 \%$ de las comisiones están aisladas; provienen de sectores políticos variados y arraigadas sin distinción alguna en las ocho unidades administrativas que se han presentado en el cuadro 1. El componente principal sólo abarca, durante este periodo, el $60 \%$ del conjunto de las comisiones, y el grado medio disminuye de manera considerable, en al menos cuatro puntos. Este declive pone en tela de juicio las posibilidades de intercambio o de coordinación que caracterizan la red hasta 1980. Sin embargo, los indicadores que se han presentado no nos permiten afirmar que los vínculos que se han establecido son más bien la expresión de una lógica neocorporativista de compensación o de un intercambio de evaluación de competencias o de conocimientos. Estas dos fases se presentarán detalladamente en los dos puntos siguientes, dónde precisamente haremos una distinción entre estas dos lógicas, gracias al análisis separado de los vínculos exogámicos y endogámicos (ver anexo 4$)^{10}$.

\subsection{Las CEP, instancias centrales de los mecanismos de compensación (1910- 1980)}

La red de las comisiones en 1910, además de ser pequeña, también está muy fragmentada y es poco inclusiva. Esto explica que los resultados de la densidad exogámica de las comisiones y de los actores no sean significativos (ver anexo 4), es decir, que no difieren de manera significativa de lo que podría ser fruto del azar. Cabe recalcar, no obstante, que el nivel de densidad exogámico de las CEP - que hemos clasificado por temáticas políticas - es muy débil, dado que sólo el $18 \%$ del conjunto de las "parejas" censadas dentro de la matriz presentada en el anexo 4 está interrelacionado (densidad superior al $0 \%$ ). Dicho de otra manera, a principios del siglo $\mathrm{XX}$, las temáticas políticas dentro del sistema comisionista no se definían, o poco, según dinámicas de coordinación con otras políticas.

\footnotetext{
${ }^{10}$ Las tablas de densidad deben leerse de la manera siguiente: la densidad interna de cada sector (relaciones endogámicas) corresponde a la diagonal, mientras que la densidad intersectorial (relaciones exogámicas) la hallamos por encima y por debajo de la diagonal. Para jerarquizar estos resultados y permitir que los sectores emerjan de manera más o menos exogámicas exogámica - arriba a la izquierda y abajo a la derecha respectivamente -, las líneas y las columnas de la matriz se han permutado sobre la base de la media de densidad intersectorial.
} 
Hallamos la explicación de esta debilidad de los mecanismos de coordinación en dos elementos principales: el primero remite al estatuto aún relativamente embrionario del sistema comisionista a principios del siglo XX (Arnold 1969: 2), que se limita, desde su creación a mediados del siglo XIX, a temáticas muy específicas, a la imagen de la política territorial, que cuenta con más de la mitad de las CEP activas en 1910. Al ser limitadas, las temáticas políticas sobre las cuales intervienen las comisiones, las posibilidades de coordinación exogámica entre temáticas diferentes son escasas. El segundo elemento es la muy débil representación de las asociaciones de intereses dentro de las CEP. En efecto, tal y como lo pone de manifiesto la tabla de densidad relativa a la afiliación de los actores de la red $2 m$-core (anexo 3 ), éstas están ausentes de nuestra submuestra. Hallamos la explicación de esta laguna, en parte, en el hecho de que las asociaciones centrales cumplen a menudo directamente, desde finales del siglo XIX, con algunas tareas públicas de las que el Estado no se encarga, como la formación profesional o la recogida de datos estadísticos (Mach 2006a). Esta situación tiende a limitar la lógica de representación del sistema comisionista.

Observamos una primera evolución cuando estalla la Primera Guerra Mundial. Las nuevas tareas estatales que conlleva la gestión del conflicto obligan a la administración helvética, poco desarrollada, a solicitar actores privados, en particular las asociaciones de intereses que constituían el bloque burgués ${ }^{11}$ y que han desempeñado desde esa época un papel cada vez más importante dentro del sistema comisionista (Baumann y Moser 1999: 45). Esta evolución también se observa en esa misma época, en particular en Francia, dónde se desarrolla considerablemente el número "cuerpos intermedios", como los Consejos Superiores de la red de ferrocarriles, o de los seguros sociales (Chatriot y Lemercier 2002).

Este proceso suscita, dentro de estas asociaciones, un primer debate sobre la forma que tendría que tener la institución encargada de acoger la representación de los intereses particulares frente al Estado federal, debate que también tienen en esa misma época en Francia (Chatriot 2007). Los artesanos apelan a la creación y a la formalización de una Cámara Económica, órgano oficial que se tendría que caracterizar por una representación paritaria entre la industria, los artesanos, el campesinado y los obreros. Esta cámara se encargaría de tomar una posición respecto a las cuestiones de política económica y obraría, en este sentido, como una instancia consultiva y de evaluación para el Gobierno. La gran patronal de la exportación, compuesta mayoritariamente por la Unión Suiza del

\footnotetext{
${ }^{11}$ Coalición creada en el cambio de siglo para hacer frente al avance del movimiento obrero, y fundada sobre la integración del campesinado a en las élites burguesas más tradicionales. Comúnmente, esta coalición abarca la Unión Suiza del Comercio y de la Industria (USCI o Vorort), la Unión Central de las Asociaciones Patronales Suizas (UCAPS o UPS), la Unión Suiza de Artes y Oficios (USAM) y la Unión Suiza de Campesinos (USP). Respecto a la génesis de esta alianza, véase Baumann (1993) y Humair (2004: 656-734).
} 
Comercio y de la Industria (USCI) y por la Unión Central de las Asociaciones Patronales (UCAPS), así como la Asociación Suiza de Banqueros (ASB) se oponen a esta creación, dado que temen que se instituya esta cámara según un principio de paridad entre asalariados y patronos, y que se haga demasiada publicidad de sus actividades. Estos temores preocupan a los círculos patronales, sobre todo teniendo en cuenta que el final de la Primera Guerra Mundial coincide con un periodo de fuertes tensiones con el movimiento obrero, que culmina en 1918 con la huelga general. Integrar a los obreros en una base formal e indiferenciada dentro de la organización que tenía que desempeñar un papel importante a la hora de definir las políticas públicas no era una opción, pues, para los representantes de los intereses patronales. Estos intereses reivindican que se mantenga un statu quo institucional del que se beneficien instituciones como las CEP (Schmid 1983: 122ss.). La precariedad relativa que caracteriza el sistema comisionista a nivel institucional se manifiesta aquí como una característica de cuyos intereses más organizados pretenden sacar provecho. Las CEP, que no disponen ni de presupuesto ni de locales en condiciones, no están sometidas, por otra parte, a ninguna otra reglamentación particular que regularía la representación de los intereses privados para el Gobierno o de definir formalmente y de manera permanente qué intereses se podrían asociar o no a las actividades de una comisión. Las características de un sistema comisionista permiten, pues, declinar la lógica de representación de manera autorregulada, articulada alrededor de la relación de fuerza social y política del momento entre los diferentes intereses sociales y económicos organizados. Sin embargo, y es una constante durante la mayor parte del siglo XX, la gran patronal industrial de la exportación es la asociación dotada de la mayor capacidad de influencia política en Suiza (Guex 2003: 542).

Los años 20 están marcados por el desarrollo de esta lógica de integración informal dentro de las CEP. Para evitar que se reproduzcan las condiciones sociales y políticas que provocaron la huelga general de 1918, las élites dirigentes adoptan respecto al movimiento obrero una táctica de "represión / cooptación" que consiste en marginar a los sindicatos revolucionarios y en integrar corrientes más moderadas. El segundo eje se lleva a cabo en las CEP: éstas representaban, en muchos aspectos, el lugar dónde se institucionalizaba una conciliación asimétrica de intereses divergentes, lo cual permitía neutralizar los riesgos de conflictos sociales. La integración de los sindicatos se opera, en efecto, sobre una base considerablemente minoritaria en comparación con los intereses del bloque burgués (Mach 2006a). Se crean pues, a mediados de los años 20, varias comisiones implicadas en la temática de las políticas económicas y que integran, por primera vez, a representantes de los obreros, siguiendo el patrón de la Comisión de Estudio de los Precios, de la Comisión consultiva para las cuestiones relativas a los 
REDES- Revista hispana para el análisis de redes sociales

Vol.21,\#10, Diciembre 2011

http://revista-redes.rediris.es

salarios, de la Comisión de Estadística de Asuntos Sociales o de la Comisión de Investigación en Economía. Tal y como menciona Pavillon (2001: 110), el propósito de estas comisiones es "crear el marco favorable para una concertación entre los diferentes grupos de intereses", en particular entre el capital y el trabajo, a la hora de reducir los costes de producción, y, en primer lugar, de los precios y de los salarios.

Por primera vez, nos encontramos, dentro de las CEP, en el centro de una dinámica de concordancia que pone en relación, dentro de un marco institucional poco reglamentado, las asociaciones del bloque burgués y los sindicatos obreros, en particular en temas relativos a la política económica. Este desarrollo constituye un "giro ideológico" respecto a la situación de 1918 (Degen y Kübler 1998: 131ss.). En efecto, la mayoría de los miembros de estas comisiones representa al ámbito de los negocios, mientras que los escasos representantes de los trabajadores se caracterizan por su fidelidad al orden burgués (Pavillon 2001). A mediados de los años 20, la Unión Sindical Suiza, principal asociación central de los sindicatos obreros, está representada en casi todas las comisiones del Departamento de Economía. Una evolución, que se podría calificar de sintomática, de esta participación en las instancias del poder, se acompaña, en 1927, de la renuncia definitiva al principio de la lucha de clases (Degen y Kübler 1998: 128-129). Paralelamente a una integración progresiva de los principales intereses económicos y sociales, la crisis de los años 30 contribuye a dar a los expertos "un papel decisivo en un contexto que escapa, de lejos, al control democrático" (Pavillon 2001: 110). Como consecuencia, el sistema comisionista se desarrolla y cuenta con 71 comisiones permanentes en 1937.

Las premisas de una red exogámica (1937)

Tal y como lo indican las tablas de densidad relativas a los actores y a las comisiones (anexos 2 y 4 ), este desarrollo se traduce en un aumento de las relaciones exogámicas, a partir de las cuales se desarrollan lógicas de coordinación y de compensación. En efecto, contrariamente a la situación de 1910, los presidentes o los secretarios de las principales asociaciones de intereses aparecen en la tabla de densidad de los actores (anexo 3). Aunque, una vez más, nuestros resultados de densidad exogámicos no son significativos (los motivos que explican la presencia de representantes de diferentes intereses podrían ser fruto del azar), esta evolución nos invita a pensar que los procesos de concertación entre los intereses patronales y los sindicales, que ilustrábamos anteriormente con los ejemplos de las comisiones económicas creadas en los años 20, tienden a generalizarse en el conjunto del sistema. La tabla de densidad relativa a las temáticas políticas en las cuales se implican las comisiones de 1937 (anexo 4) es también representativa del alcance de este cambio, dado que nuestros resultados de 
densidad exogámica, esta vez, son significativos. En efecto, el porcentaje de parejas temáticas políticas que están interrelacionadas ha aumentado de manera importante y, esta vez, representa el 30\% del conjunto de las mismas. Entre las políticas dotadas de mayor densidad exogámica (subrayadas en amarillo en el anexo), hallamos: los seguros sociales, las políticas aduanera, financiera, comercial, sanitaria, y las cuestiones relativas a las normas del sistema de medidas. Dicho de otra manera, estas políticas están altamente predispuestas a ser definidas, dentro del sistema comisionista, en relación con otros temas. Los procesos de concertación tienden a tratar varias políticas a la vez, pero se centran mayoritariamente en las políticas económicas y sociales. Al contrario (subrayado en marrón en el anexo), cuando se trata de temas como las políticas científicas, culturales, agrícolas o militares, el nivel de densidad exogámica se mantiene débil: estas políticas se definen de manera relativamente autárquica.

$\mathrm{Si}$ el desarrollo de las relaciones exogámicas es relativamente importante respecto a la situación de 1910, varios índices indican, sin embargo, que el nivel de log-rolling y de bargaining entre los diferentes intereses económicos y sociales organizados que están relacionados con varias políticas, es relativamente marginal. Así pues, los representantes de las asociaciones de intereses tan sólo ocupan una posición secundaria dentro de la tabla de densidad de los actores (anexo 3), y constituyen una parte marginal de los individuos centrales al nivel de grado ( 3 actores sobre 10, ver anexo 6) y de intermediación ( 0 actores sobre 10, ver anexo 7). Por otra parte, las temáticas políticas cuya densidad exogámica es más elevada siguen siendo, en 1937, variadas. En efecto, la mayoría de las políticas económicas o sociales (ver anexo 2 ) no desarrollan entre ellas prácticamente ninguna relación exogámica. El valor de los vínculos que unen las comisiones entre ellas también tiende a demostrar cierta marginalidad de las dinámicas de log-rolling y de bargaining, dado que todas las relaciones exogámicas censadas lo son tan sólo gracias a un miembro en común (ver anexo 5). Así pues, estas relaciones se mantienen considerablemente al margen en comparación con las relaciones endogámicas; en efecto, algunas de las comisiones que trabajan sobre asuntos similares comparten hasta 7 miembros en común, mayoritariamente sobre la problemática de los seguros sociales.

Esta situación indica que aunque desde la Primera Guerra Mundial las CEP representan cada vez más un lugar de integración y de encuentro entre los actores patronales, sindicales, campesinos, políticos y administrativos, aún no constituyen, de manera global, una instancia dentro de la cual se opera principalmente una conciliación de intereses. Varios motivos contribuyen a explicar estos resultados. Las principales asociaciones patronales disponen a menudo de un acceso directo al Gobierno, con lo cual 
REDES- Revista hispana para el análisis de redes sociales

Vol.21,\#10, Diciembre 2011

http://revista-redes.rediris.es

pueden prescindir de la intervención de las CEP y no establecen mecanismos de logrolling (Jost 1999: 33; Schmid 1983: 125ss.).

Por otra parte, los representantes del movimiento obrero se integran progresivamente al sistema comisionista desde los años 20, pero esta integración aún no se puede dar por acabada a mediados de los años 30. En general, se recalcan dos fechas para dar constancia de la pacificación y de la institucionalización de las relaciones entre patronos y obreros, así como de una integración más global de la izquierda dentro del sistema gubernamental: la primera es 1937, con el acuerdo de "Paz del trabajo" entre los sindicatos y la patronal de la metalurgia y de la maquinaria. Este acuerdo, que designa una resolución de los conflictos colectivos entre patronos y asalariados mediante una negociación, implica renunciar explícitamente a las medidas de lucha como la huelga y el lock-out, y deja su huella durante más de 60 años de relaciones industriales. La segunda fecha es 1943, con la elección de Ernst Nobs en el Consejo Federal, primer socialista que consigue entrar en el Gobierno federal (Degen et Kübler 1998: 137; Jost 1999: 219). Mas, el final de los años 30 y la inmediata posguerra aparecen como un periodo bisagra de institucionalización de las relaciones entre asociaciones del trabajo y del capital; nuestro análisis de red, que da constancia de una realidad institucional establecida, no puede poner en evidencia este proceso para el año 1937. En efecto, a pesar de este proceso de integración, los años 40 aún están marcados por una serie de situaciones muy conflictivas al nivel de las relaciones industriales entre patronos y obreros (Mach 2006b: 245). La dinámica sólo parece funcionar por completo a partir de los años 50.

La situación del año 1938 que acabamos de exponer se radicaliza considerablemente durante los años 40 y 50: en efecto, este periodo, cuyo inicio está marcado por la Segunda Guerra Mundial, constituye una nueva aceleración de la participación de las asociaciones de intereses en el sistema gubernamental, ya que la guerra desempeña, en este sentido, un papel similar a la Primera, extendiendo las funciones asumidas por las asociaciones de intereses, pero también reforzando su papel frente a las autoridades (Lanzalaco 2008: 307-308). En efecto, en Suiza se establece un sistema administrado por el Estado, pero considerablemente condicionado por los intereses privados, dado que la mayoría de los colaboradores de las Oficinas de la Economía de Guerra provienen de la industria privada. Los representantes de los trabajadores también se integran a este dispositivo, pero sobre una base sumamente limitada y subordinada. La regulación económica se elabora, pues, a partir de este periodo, en torno al eje que constituyen conjuntamente la administración y las asociaciones de intereses (Jost 1999: 204ss.; Werner 2000: 41). Cabe subrayar que esta práctica consta en la Constitución a partir de 1947, a través de la revisión de los artículos económicos (art. 32), que reconocen el 
papel de las asociaciones de intereses dentro del proceso legislativo y de la aplicación de las políticas públicas. Esta institucionalización favorece de manera importante el reajuste de las fases de decisión referentes a las principales temáticas políticas en favor de la fase pre-parlamentaria, en particular dentro de las comisiones extraparlamentarias (Kocher 1967: 250ss.).

Los Treinta Gloriosos de la coordinación (1957)

Nuestro análisis de red para el año 1957 permite apreciar el alcance del cambio que se opera respecto a la situación de 1937: la tabla de densidad relativa a la afiliación de los actores de la red 2-slices (anexo 3), así como el cuadro que recapitula las densidades (anexo 2), ponen de manifiesto de manera muy clara, esta vez sí, los tres tipos de asociaciones de intereses a través del trío de cabeza de los actores cuya densidad exogámica es la más elevada. Nuestros resultados también son significativos en otros aspectos: las asociaciones entre grupos de intereses dentro de las comisiones aparecen bajo una forma que no puede ser fruto del azar. Los índices de centralidad individual confirman esta evolución, dado que respectivamente 8 y 7 de los 10 actores cuya centralidad individual y de intermediación es la más alta provienen de estas asociaciones. El trío de cabeza de la centralidad de grado es, por sí solo, sintomático de la dinámica neocorporativista en juego, dado que está compuesto por dirigentes de tres de las principales asociaciones centrales suizas: en primera posición, Edmund Wyss, secretario de la Unión Sindical Suiza de (USS), que en 1957 está presente en 12 comisiones distintas, la mayoría sobre la política económica, comercial y aduanera. En segunda posición encontramos a Leonhard Derron, director de la Unión Central de las Asociaciones Patronales Suizas (UCAPS), que está presente en 9 comisiones, todas ellas relacionadas con las temáticas de la política económica y de los seguros sociales. En tercera posición, Rudolf Reichling, presidente de la Unión Suiza de los Campesinos (USP) y parlamentario federal agrario, está presente en 12 comisiones de política agrícola, comercial y económica. Cabe mencionar, en séptima y octava posición, a Ernst Geyer, secretario del Vorort (USCI), que está presente en 9 comisiones de política agrícola y económica, y a Manfred Fink, secretario de la Unión Suiza de Artes y Oficios (USAM), que está presente en 5 comisiones sobre la política económica y los seguros sociales. El perfil de los representantes de las asociaciones de intereses difiere sensiblemente de la situación de 1937, dado que éstos, a partir de esta época, son sobre todo secretarios y no miembros. Lejos de ser anecdótica, esta evolución remite a un proceso de distorsión del principio de milicia y a una dinámica de profesionalización de la representación de las principales asociaciones económicas y sociales dentro de las CEP. El trabajo realizado por las comisiones forma parte integrante, en efecto, del pliego de condiciones profesional de estos actores, que están en condiciones, pues, de optimizar su influencia dentro del 
sistema, al contrario de la mayor parte de los demás miembros, para los cuales esta ocupación no es la principal.

La fuerte centralidad de los representantes de los intereses económicos y sociales organizados dentro del sistema comisionista indica que la lógica de representación supera, en 1957, la lógica de evaluación de competencias. La tabla de densidad relativa a las CEP (anexo 4) indica, por otra parte, que esta lógica de representación corre a la par de una dinámica de coordinación y de negociación referente a diferentes temáticas políticas. En efecto, el $66 \%$ de las parejas censadas dentro de la tabla de densidad están relacionadas entre ellas, con lo cual nuestros resultados son, esta vez, significativos. Así es como se establece por primera vez, dentro de nuestros hitos cronológicos (anexo 4), una dinámica de coordinación macroeconómica de las políticas agrícola, económica, comercial, financiera, monetaria o laboral. Por otra parte, el valor de los vínculos que unen a las CEP entre ellas sobre una base exogámica es claramente más elevado que en 1937. Mencionemos, entre las comisiones más relacionadas sobre una base exogámica, la Comisión consultiva de la política comercial y el Comité consultivo para las cuestiones coyunturales. Estas dos comisiones, presentadas en el recuadro no 1 , tienen 9 miembros en común, sobre un total de 28 y 35 miembros respectivamente, de los cuales 6 provienen de las principales asociaciones de intereses. Podemos, pues, llegar a la conclusión de que la política comercial y la política coyuntural se definen sobre una base ampliamente coordinada, a través de los mecanismos de log-rolling entre los principales intereses económicos organizados.

Creada en 1949 por las Autoridades federales, la Comisión consultiva de la política comercial está en el centro de los mecanismos de negociaciones políticas transversales. La política comercial cobra cada vez más importancia al nivel económico y social a partir de mediados de los años 40, debido, en particular, a la liberalización de los pagos y a la emergencia del mercado europeo (Gees 1999). En efecto, esta política cristaliza las tensiones entre la economía de exportación, por una parte, y la economía doméstica, por otra parte. La tensión es particularmente importante entre los representantes del capital y de los campesinos, dado que estos últimos desean proteger su producción frente a las importaciones de productos agrícolas negociadas, en el marco de contratos comerciales bilaterales, a cambio de la exportación de bienes económicos o industriales helvéticos (Gees 1999: 158ss.). Frente a esta situación crítica, las Autoridades refuerzan su política exterior, integrando todas las fuerzas políticas propensas a establecer una política de bloqueo. Este proceso se 
expresa principalmente a través de la Comisión consultiva de la política comercial: en efecto, ésta permite canalizar las reivindicaciones comerciales del campesinado, pero también de otros grupos sociales, como los representantes de los trabajadores o los consumidores, y evitar la incertidumbre del desenlace de un proceso consultivo. Así pues, esta comisión permite a los principales grupos de intereses negociar y declinar, sobre una base autorregulada, los ejes principales de la política comercial de la época, relacionados con otros asuntos políticos (Dirlewanger et aterl 2004: 112ss.). La ley de 1952 sobre la agricultura, que protege todo el sector de las leyes de la economía de mercado, constituye el resultado principal de esta negociación (Baumann y Moser 2011). Katzenstein (1985: 78), habla, para calificar este resultado, de "policies of domestic compensation", teoría que insiste en el establecimiento de políticas de compensación interna cuyo objetivo es equilibrar, con medidas de protección del sector doméstico, las medidas de apertura económica hacia el extranjero que favorecen la industria de exportación. Nuestro análisis de red indica que las CEP son uno de los principales lugares donde se elaboran.

La dinámica del Comité consultivo para las cuestiones coyunturales, creado en 1957 por el Gobierno, es similar. Instancia de paridad entre patronos $y$ asalariados, este comité se encarga de elaborar, al igual que la Comisión de Investigación en Economía analizada por Pavillon (2001), soluciones de concordancia entre los intereses de los trabajadores y los intereses del capital respecto a una adaptación de los sueldos a los nuevos desafíos internacionales de la economía suiza de la posguerra (ver Krügle 1962: 95ss.). Una dinámica de negociación que enfrenta estos mismos sectores también interviene a nivel del establecimiento y del desarrollo de los seguros sociales (Leimgruber 2008: 116ss.). Las comisiones solicitadas para las políticas económicas y sociales a partir del final de la Segunda Guerra Mundial están, pues, más regidas por lógicas de representación de influencia que por lógicas de evaluación de competencias. No obstante, cabe mencionar que estos mecanismos de conciliación (entre estos diferentes intereses) enfrentan intereses relativamente desiguales en cuanto a medios y organización, tal y como se puede apreciar en el trabajo hecho por la Comisión encargada a partir de 1957 de elaborar la ley sobre los cárteles: en efecto, al anticipar el lanzamiento del proceso legislativo, los círculos del bloque burgués concilian y allanan las diferencias que existen entre ellos, a partir de 1953, dentro de una Comisión de los cárteles de la economía privada. Cuatro años más tarde, cuando la comisión federal inicia su tarea, este trabajo les permite formar un grupo 
REDES- Revista hispana para el análisis de redes sociales

Vol.21,\#10, Diciembre 2011

http://revista-redes.rediris.es

unitario y dejar en minoría las fuerzas anti-cárteles, compuestas por algunos outsiders económicos 0 por representantes de los consumidores que seguirán durante mucho tiempo dispersados y sin coordinación (Rebmann y Ginalski 2010).

Encuadrado $\mathbf{n}^{\circ} \mathbf{1}$. Algunas comisiones centrales de los mecanismos de log-rolling

Tal y como indican los ejemplos que figuran en el recuadro $n^{\circ} 1$, la nueva situación internacional que se perfila al final de la Segunda Guerra Mundial desempeña un papel importante en el desarrollo de las lógicas de coordinación y de compensación dentro del sistema comisionista: en efecto, el proceso de liberalización económica y el inicio de la fase de crecimiento económico aumentan las tensiones sociales, en particular entre los intereses de los campesinos, de los obreros y de los patronos. Estas tensiones tienen que ver, en particular, con la manera de administrar este crecimiento y de repartir sus frutos. Las CEP permiten canalizar e institucionalizar, aunque al margen de las instituciones políticas oficiales, estas reivindicaciones; reducen, de esta manera, los riesgos de bloqueo político. La ausencia de una reglamentación del sistema comisionista en aquella época permite a las élites dirigentes evitar una politización de límites inciertos; también permite optar por procesos de autorregulación dentro de los cuales las capacidades de organización y de influencia desempeñan un papel determinante, a fortiori en el marco de una democracia plebiscitaria. Mas, parece que en este juego, los intereses patronales suplantan, considerablemente y a menudo, las milicias sindicales, o aún más, las de consumidores. A cambio, los círculos "integrados" aprovechan los mecanismos de compensación que se instauran, protegiendo el mercado local para las milicias agrícolas, y permitiendo a los círculos obreros participar en la regulación del mercado laboral y de los sueldos, lo cual constituye una de sus más antiguas reivindicaciones (Mach 2006b: 245ss.). La red "inter-comisiones" constituye, pues, para estas asociaciones económicas y sociales, un eje de "democracia social" que compite ventajosamente contra la "democracia política". Estas asociaciones contribuyen deliberadamente a crear y a mantener una institución, en particular a través del principio del "mandato institucional", que les permite encargar el trabajo relativo a las comisiones a un número limitado de secretarios, los cuales a veces están presentes en varias decenas de comisiones. En efecto, tal y como mencionan Germann y Frutiger (1978: 107),

"los procesos de bargaining y de log-rolling exigen que las concesiones hechas en una comisión puedan ser compensadas por ventajas obtenidas en otra comisión, lo cual sólo es posible a condición de que exista un número relativamente limitado de actores principales".

Si no podemos excluir claramente que algunas asociaciones marginales limiten el número 
REDES- Revista hispana para el análisis de redes sociales

Vol.21,\#10, Diciembre 2011

http://revista-redes.rediris.es

de secretarios por cuestiones de recursos limitados, las principales asociaciones centrales disponen de recursos logísticos y económicos a menudo muy importantes, y se encuentran en el centro de las lógicas de acumulación de mandatos. La concentración de mandatos en las manos de los secretarios de estas asociaciones es menos la consecuencia de recursos débiles que una elección estratégica: en 1977, las principales asociaciones centrales orquestan, pues, una revuelta contra una directiva federal que pretende aumentar la diversidad de los miembros de las comisiones, limitando a 16 años la acumulación de mandatos. Presentada como una medida de lucha contra la lógica de representación de las CEP y contra "la oligarquía de las asociaciones de intereses" (Tages Anzeiger, 28 de julio 1977), esta directiva no sobrevive, bajo esta forma, a las protestas de las asociaciones de intereses. En efecto, se les otorgan algunas medidas de excepción, en una nueva moción de 1983 (Arbeitgeber-Zeitung, 4 de agosto 1977; Rüegg 1992: 105). Este ejemplo indica que las principales asociaciones de intereses no sólo se contentan con establecer redes de coordinación en un momento dado, sino que también actúan para mantenerlas a largo plazo, estableciendo relaciones de confianza duraderas entre los miembros que las componen. Estos mecanismos son características centrales de las economías de mercado coordinadas (Hall et Soskice 2001), de las cuales Suiza forma parte en esa época.

Así pues, el periodo comprendido entre el fin de la Segunda Guerra Mundial y los años 70 representa la edad de oro de la lógica de representación y de concordancia del sistema comisionista. En efecto, dentro de las CEP se establecen unos compromisos políticos precoces, entre las principales asociaciones de intereses, que después el Parlamento no puede cambiar con facilidad. No obstante, cabe subrayar que esta lógica no se aplica de manera indiferenciada al conjunto del sistema, dado que estas negociaciones atañen mayoritariamente a las políticas económicas y sociales (las políticas subrayadas en amarillo en el anexo 4). Al contrario, este fenómeno afecta poco a temáticas como los asuntos militares o culturales.

La coordinación entre crecimiento y crisis (1980): un momento crucial

Tal y como indica el anexo 4, la estructura de la red, que se articula en torno a las políticas de compensación, se mantiene ampliamente entre 1957 y 1980: el $80 \%$ de las parejas censadas dentro de la matriz están relacionadas entre ellas en estas fechas, y el resultado global es significativo. Cabe mencionar de nuevo, entre las Comisiones más interrelacionadas (ver anexo 5), la Comisión consultiva de la política comercial (35 miembros en total), que comparte 8 miembros con la Comisión de expertos para las tarifas aduaneras y la limitación de la importación, y 6 miembros con la Comisión para la lucha contra las crisis y la creación de empleo. Aunque la situación de 1980 es, en este 
REDES- Revista hispana para el análisis de redes sociales

Vol.21,\#10, Diciembre 2011

http://revista-redes.rediris.es

sentido, muy similar a la de 1957 merecen ser mencionadas dos evoluciones significativas: la política laboral, cuya densidad exogámica aumenta como la del conjunto de las políticas económicas y sociales, gana más importancia; la política agrícola, al contrario, se desestima cada vez más. El interés del aumento de la densidad exogámica de la política laboral aparece más claramente a la luz del carácter fundamentalmente sectorial de la regulación de este mercado en Suiza. Por otra parte, esta regulación nunca ha participado activamente en la coordinación de las políticas macroeconómicas ${ }^{12}$ (monetaria, financiera y salarial), al menos en términos comparables a la situación de otros países, como Austria o Suecia (ver Mach 2006b: 236; 256; Scharpf 1991). Nuestros resultados tienden a indicar que, contrariamente a lo que se considera comúnmente, el nivel legislativo no está desprovisto de coordinación. Sin embargo, de lo que aquí se trata, fundamentalmente, es de una realidad coyuntural. En efecto, las décadas de crecimiento de la posguerra están marcadas por una extensión importante de las reglamentaciones federales del mercado laboral: cabe mencionar en particular la ley federal que permite extender el campo de aplicación de las CCT de 1957, la revisión de la ley federal sobre el trabajo de 1964, o la revisión del Código de las Obligaciones de 1971 (Mach 2006b: 259). Mas, estas reglamentaciones federales han sido elaboradas, probablemente, a través de mecanismos de log-rolling con otras temáticas (ver anexo 4). Por otra parte, la crisis ${ }^{11}$ económica de los años 70 parece haber reforzado la dinámica de interdependencia de la política laboral con las políticas económicas y comerciales, tal y como indica la tabla recopiladora del anexo 2 . En paralelo, la temática agrícola retrocede en nuestra tabla de densidad, y las asociaciones de campesinos aparecen marginadas en la lista de los actores más exógamos (anexo 3). Estamos aquí frente al inicio de una fase de debilitamiento importante de esta temática y de estos actores dentro de los mecanismos de coordinación del ámbito comisionista.

\subsection{Las CEP frente a la internacionalización y a la crisis del neocorporativismo: un papel considerablemente redefinido}

Tal y como hemos visto, la red de las comisiones, entre 1980 y 2000, cambia profundamente de morfología. El anexo 4, que expone resultados significativos, indica que esta evolución también se puede percibir a nivel de las relaciones exogámicas, dado que sólo el $51 \%$ del conjunto de las parejas censadas en la tabla de densidad están conectadas entre ellas. Así pues, asistimos a una ruptura de relaciones entre varias políticas (ver anexo 2, subrayado en amarillo). Por otra parte, las parejas de comisiones más relacionadas en términos exogámicos sólo comparten como máximo 3 miembros en

\footnotetext{
12 En efecto, las reglamentaciones del mercado laboral están codificadas en varios niveles jerárquicos: en algunas leyes federales, en los convenios colectivos de trabajo (CCT) o en los reglamentos de las empresas. No obstante, la mayor parte de las normas se elabora en el marco de las CCT.
} 
el año 2000, contra 9 veinte años antes (anexo 5). Esto contribuye a cuestionar las posibilidades de log-rolling, dado que un mecanismo de negociación y de intercambio de favores entre dos comisiones no puede esquivar la cuestión de la formación de mayorías. No obstante, si 5, 7 ○ 9 miembros en común, sobre un total de una veintena, pueden coordinar su posición y elaborar una posición mayoritaria, no ocurre lo mismo cuando esta negociación se efectúa solo entre 2 o 3 miembros.

Este desarrollo remite a una serie de cambios estructurales de fondo, a nivel interno y externo, a los que el sistema comisionista hace frente desde los años 80. A nivel externo, el proceso de internacionalización "directo" de los procesos de decisión, es decir, el impacto de los tratados internacionales sobre la producción de normas a nivel nacional, tiende, en efecto, a limitar las posibilidades de consulta/coordinación inherentes a la fase pre-parlamentaria, y afecta al poder de decisión del sistema comisionista (Sciarini et alter 2002). En efecto, en 1990-1992, las comisiones extraparlamentarias no participan en la preparación del programa Eurolex, vinculado con las negociaciones sobre el Espacio Económico Europeo, dado que el ritmo de ejecución de las tareas que impone la Comunidad Europea se considera demasiado rápido para adaptarse al de una comisión que, debido a sus condiciones de trabajo, es relativamente lento (Germann 1996: 99100). Esta inadecuación progresiva entre estas nuevas exigencias políticas y las especificidades del sistema comisionista conduce, en particular, a un reajuste del número de comisiones y a la supresión de varias. Por otra parte, desde el año 2000, asistimos a una aceleración de este fenómeno, con una dinámica que cuestiona el carácter militante y la lógica de representación de las CEP (véase Rebmann y Mach 2012).

A nivel interno, cabe subrayar el proceso de reforma del sistema comisionista que se desarrolla a partir de los años 70, y que prosigue durante los 30 años siguientes. Así pues, varias medidas invitan a las instancias encargadas de nombrar a los miembros de las CEP a mejorar la representatividad de éstas, y a priorizar la evaluación de competencias científicas frente a la defensa de intereses. Es el caso de la ordenanza sobre las comisiones extraparlamentarias de 1996, que limita la acumulación de mandatos a 12 años y suprime las medidas de excepción que se acordaron para las asociaciones de intereses 13 años antes (Rebmann y Mach 2012). Por otra parte, en la línea del cuestionamiento de los mecanismos neocorporativistas a nivel internacional (véase Streeck 2006), también asistimos a una reconfiguración de las relaciones de fuerza y de las estrategias de alianza entre los diferentes intereses sociales y económicos organizados. Ésta viene, en mayor parte, tras la emergencia, a partir de los años 90, de una nueva generación de "autoemprendedores" formados en los principios del management de tipo anglosajón que en general le dan muy poca importancia a los 
principios de conciliación y de coordinación. Por otra parte, estos actores tienden a desestimar las instancias de representación nacional a favor de lugares de decisión europeos o internacionales (David et alter 2009b). Esta evolución contribuye a fragilizar las asociaciones de intereses "tradicionales", cuya función de regulador social se cuestiona debido a que una parte no despreciable de sus miembros se retira, y a la creación de un cierto número de asociaciones "disidentes" que ya no desean seguir el juego de la concordancia (David et alter 2009a). Los sindicatos, por su parte, redefinen ampliamente su posición adoptando una postura más agresiva desde los años 90: se definen cada vez más como una fuerza de oposición y rehabilitan la huelga en su repertorio de acciones (Oesch 2007: 341ss.). La confluencia de estos dos elementos contribuye a poner fin al periodo de oro de las CEP como expresión institucional del neocorporativismo y de la concordancia (Rüegg 1992: 110; Sägesser 2006).

Nuestros resultados indican que estos cambios afectan en particular a la política agraria, cuyos vínculos con otras temáticas económicas y sociales disminuyen de manera sustancial (véase anexo 2). Por primera vez desde 1937, esta política se encuentra aislada de la política laboral o financiera, lo cual pauta la pérdida de interés de esta temática dentro de las políticas de compensación. En efecto, en la línea de las negociaciones del Uruguay Round, que inician la liberalización progresiva del comercio de productos agrarios, los intereses económicos helvéticos más internacionalizados y una parte de los altos funcionarios públicos cuestionan los mecanismos proteccionistas a favor de los intereses de los campesinos, en particular a través de la abolición de subvenciones a la exportación y de precios garantizados a favor de los productos agrarios (Sciariniyt von Holzen 1995: 63; Baumann y Moser 2011).

Hallamos la principal expresión institucional de este cuestionamiento de las lógicas de coordinación a favor de una relación más conflictiva dentro de las CEP: en efecto, una parte importante de los intereses económicos o sindicales abandona su representación dentro del sistema comisionista, o como mínimo se retira de las lógicas de "plurievaluación". La acumulación de mandatos, que hasta entonces era el eje estructural de la coordinación transversal, se convierte, para las principales asociaciones de intereses, en una obligación material y financiera, y ya no constituye un recurso que se trata de mantener o de desarrollar.

$\mathrm{Si}$, tal y como acabamos de ver, la red "inter-comisiones" pierde consistencia, conviene mencionar que un núcleo de relaciones exogámicas se mantiene en el año 2000. En efecto, las asociaciones de intereses se mantienen ampliamente entre los actores más exogámicos de la red (anexo 3) y, por otra parte, refuerzan mutuamente sus relaciones (nuestros resultados de densidad exogámica son significativos). Es más, tal y como se 
REDES- Revista hispana para el análisis de redes sociales

Vol.21,\#10, Diciembre 2011

http://revista-redes.rediris.es

indica en el cuadro recopilador (anexo 2), las tres densidades exogámicas más elevadas remiten exclusivamente a relaciones entre las asociaciones de intereses. Esta evolución también se ve confirmada por los índices de centralidad individuales, dado que 9 de cada 10 personas de las más centrales en términos de grado y de intermediaridad provienen de estas asociaciones (anexo 6).

¿Cómo explicar esta situación cuando, tal y como acabamos de ver, una parte importante de la comunidad económica se aleja de las CEP, o como mínimo, redefine los términos de su presencia? Básicamente, hallamos la explicación en la dinámica de reorganización, de cooperación - incluso de fusión - creciente entre las asociaciones "tradicionales" ${ }^{13}$, que se perfila a finales de los años 90, y con la cual éstas pretenden hacer frente a las dificultades internas y externas mencionadas anteriormente (véase David et alter 2009a, Kriesi 2006 o Oesch 2007). Un núcleo de relaciones se mantiene, pues, entre estas asociaciones "tradicionales" dentro de las CEP, lo cual contribuye a compensar esta evolución y a limitar la disgregación de las relaciones exogámicas.

Tal y como indican los anexos 2 y 4 , la persistencia de estas relaciones intersectoriales interviene, básicamente, a nivel de la política aduanera, que está en el centro de las preocupaciones políticas al final de los años 90, junto con las negociaciones relativas a los acuerdos de la Organización Mundial del Comercio y los acuerdos bilaterales de 1999 con la Unión Europea (UE). En el segundo caso, las negociaciones atañen a una apertura recíproca de los mercados en siete ámbitos particulares: la libre circulación de personas, los obstáculos técnicos al comercio, los mercados públicos, la agricultura, el transporte aéreo y terrestre, así como la participación de Suiza en los programas de investigación de la UE. En este sentido, no sorprende que las densidades exogámicas más elevadas de nuestra tabla (anexos 2 y 4 ) sean precisamente las de las relaciones que la política aduanera mantiene con estas temáticas. A pesar de su cuestionamiento, el sistema comisionista sigue siendo, pues, al menos parcialmente, un lugar dentro del cual se coordinan estas diferentes temáticas. En el marco de este proceso, la libre circulación de personas representa el principal escollo del conjunto del proyecto, dado que enfrenta, en particular, a los sindicatos con las asociaciones económicas. Mientras que éstas ven el conjunto de los acuerdos bilaterales como una prioridad de primer orden - con el propósito de estabilizar las relaciones aduaneras y comerciales de Suiza con la UE -, el referéndum lanzado por los círculos conservadores antieuropeos les obliga a buscar activamente el apoyo del mundo laboral. Sin embargo, los representantes sindicales

\footnotetext{
${ }^{13}$ Cabe mencionar, en particular, la fusión, en el año 2000, de la Unión Suiza del Comercio y de la Industria (USCI) y de la Sociedad para el Desarrollo de la Economía Suiza (SDES) - a partir de la cual se crea Economiesuisse -, o también, entre los intereses laborales, el proceso de fusión que se inicia en 1988 entre varios sindicatos ramificados, cuyo número pasa de 20 a 5 en pocos años (véase Oesch 2007: 360ss.).
} 
supeditan su apoyo al establecimiento de medidas de re-regulación del mercado laboral, en particular a través de la lucha contra la depreciación de los sueldos y del refuerzo político de los convenios colectivos de trabajo (véase Oesch 2011, Afonso 2010). Este ejemplo indica que, aunque las dinámicas de conciliación y de compensación tienden a debilitarse dentro de las CEP entre 1980 y 2000, este proceso sigue inacabado: la disgregación de las relaciones exogámicas se produce básicamente desde el margen de la red, dado que un núcleo de coordinación y de conciliación se mantiene, sobre una base más limitada, respecto a las políticas de compensación doméstica, y se articula en torno a las principales asociaciones que defienden los intereses del trabajo y del capital.

\section{Conclusión}

Las relaciones que se establecen entre las comisiones extraparlamentarias implicadas en temáticas diferentes (relaciones que hemos designado como exogámicas), gracias al mecanismo de acumulación de mandatos, están en el origen de las lógicas de conciliación y de compensación entre las principales asociaciones de intereses, a través de mecanismos de log-rolling y de bargaining. Esta red, que aparece como la base estructural de un funcionamiento de tipo neocorporativista, se densifica de manera continua entre 1910 y 1980, con una aceleración marcada a partir de la Segunda Guerra Mundial. Aunque hasta ese entonces se había intuido el carácter neocorporativista de las CEP, éste nunca se había demostrado a nivel del conjunto del sistema.

No obstante, conviene observar que esta lógica neocorporativista de compensación no se establece de manera uniforme en el conjunto de las comisiones: en efecto, la desarrollan sobre todo las principales asociaciones de intereses, cuando se trata de temáticas económicas y sociales, y en particular de las problemáticas relativas al mercado doméstico y de exportación. Al contrario, los círculos universitarios o científicos están casi totalmente excluidos de estas dinámicas neocorporativistas, de la misma manera que la política cultural, que para nuestras cinco fechas presenta un nivel de densidad exogámica de los más bajos.

No obstante, entre 1980 y 2000 asistimos a un claro declive de la densidad de la red de las comisiones extraparlamentarias, que pone fin a la mayor parte de las relaciones exogámicas entre diferentes políticas. Esta evolución indica un cuestionamiento importante de la estructura de coordinación y de compensación que caracterizaba el sistema comisionista desde el final de los años 30. Hallamos su origen principalmente en tres factores: el proceso de reforma del sistema comisionista que se inicia en los años 70, y que pretende limitar la lógica de representación en favor de la lógica de evaluación, el proceso de internacionalización que afecta a Suiza a partir desde los años 80, y que reduce la importancia de la fase pre-parlamentaria oficial, y por último, un cambio de 
REDES- Revista hispana para el análisis de redes sociales Vol.21,\#10, Diciembre 2011

http://revista-redes.rediris.es

preferencias y de repertorio de acciones de un cierto número de asociaciones económicas y sociales, que progresivamente se alejan de los mecanismos de cooperación transversal característicos de los regímenes neocorporativistas. No obstante, a pesar de esta evolución, se mantiene un núcleo exogámico, sobre una base más limitada, entre las asociaciones de intereses "tradicionales" respecto a algunas políticas económicas y sociales.

La similitud de la evolución que hemos expuesto en esta contribución con la de la red interempresas, tal y como la describen Schnyder et alter (2005), indica que los cambios que se observan dentro de la estructura comisionista forman parte, sin lugar a dudas, de un cambio más global del modo de organización del capitalismo suizo a lo largo de las dos últimas décadas del siglo XX. En efecto, si hasta los años 80-90 Suiza se puede vincular claramente con la tipología de economías de mercado dichas "de coordinación" o neocorporativistas (Katzenstein 1985; Schröter 1999; Hall y Soskice 2001), la última década del siglo XX se caracteriza por un cuestionamiento profundo de este principio, en particular con un extenso programa de desregulación y de liberalización de la economía suiza (Mach 2006b). El presente estudio indica que, lejos de limitarse a la esfera económica, este cuestionamiento también se manifiesta en la organización estatal y en las relaciones institucionales entre el Estado y los grupos de intereses.

\section{Bibliografía}

Afonso, Alexandre (2010). Policy concertation, Europeanization and new political cleavages: The case of Switzerland. European Journal of Industrial Relations 16(1), 5772.

Arnold, Karl (1969). Verwaltungs- und Regierungstätigkeit durch eidgenössische Kommissionen. Winterthur: Verlag Hans Schellenberg.

Baumann, Werner (1993). Bauernstand und Bürgerblock : Ernst Laur und der Schweizerische Bauernverband 1897-1918. Zurich: Orell Füssli.

Baumann, Werner y Peter Moser (1999). Bauern im Industriestaat : agrarpolitische Konzeptionen und bäuerliche Bewegungen in der Schweiz 1918-1968. Zurich: Orell Füssli.

Baumann, Werner y Peter Moser (2011). Politique agricole. Dictionnaire historique de la Suisse (DHS), versión del 25.01.2011 (traducido del alemán), url: http://www.hls-dhsdss.ch/textes/f/F13789.php

Borgatti, Stephen, Martin Everett y Linton Freeman (2002). Ucinet 6 for Windows : Software for Social Network Analysis. Harvard: Analytic Technologies. 
REDES- Revista hispana para el análisis de redes sociales

Vol.21,\#10, Diciembre 2011

http://revista-redes.rediris.es

Chatriot, Alain (2002). La démocratie sociale à la française. L'expérience du Conseil national économique 1924-1940. Paris: La Découverte.

Chatriot, Alain (2007). Les apories de la représentation de la société civile. Débats et expériences autour des compositions successives des assemblées consultatives en France au XXe siècle. Revue française de droit constitutionnel 71, 535-555.

Chatriot, Alain y Claire Lemercier (2002). Les corps intermédiaires. In Duclert, Vincent y Christophe Prochasson (dir.), Dictionnaire critique de la République. Paris: Flammarion, 691-698.

Chatriot, Alain y Claire Lemercier (2008). Une histoire des pratiques consultatives de I'Etat. In Offerlé, Michel y Henri Rousso (dir.), La fabrique interdisciplinaire. Histoire et science politique. Rennes: Presses Universitaires de Rennes, 191-203.

Crozier, Michel y Erhardt Friedberg (1977). L'acteur et le système : les contraintes de I'action collective. Paris: Ed. du Seuil.

David, Thomas, Stéphanie Ginalski, André Mach y Frédéric Rebmann (2009a). Networks of Coordination: Swiss Business Associations as an Intermediary between Business, Politics and Administration during the 20th Century. Business and Politics 11(4), 1-38.

David, Thomas, Stéphanie Ginalski, Frédéric Rebmann y Gerhard Schnyder (2009b). The Swiss business elite between 1980-2000 : declining cohesion, changing educational profile and growing internationalization. In Sattler, Friederike (dir.), European economic elites : between a new spirit of capitalism and the erosion of state socialism. Berlin: Duncker \& Humblot, 197-220.

De Nooy, Wouter, Vladimir Batagelj y Andrej Mrvar (2005). Exploratory Social Network Analysis with Pajek. New-York: Cambridge University Press.

Degen, Bernard (2010). Référendum populaire. Dictionnaire historique de la Suisse (DHS), versión del 26.08.2010 (traducido del alemán), url: http://www.hls-dhsdss.ch/textes/f/F10387.php

Degen, Bernard y Markus Kübler (1998). Die Gewerkschaften zwischen Integration und Ausgrenzung. In Guex, Sébastien et alter (dir.), Krisen und Stabilisierung. Die Schweiz in der Zwischenkriegszeit. Zurich: Chronos.

Dirlewanger, Dominique, Sébastien Guex y Gian-Franco Pordenone (2004). La politique commerciale de la Suisse de la Seconde Guerre mondiale à l'entrée au GATT (19451966). Zürich: Chronos.

Frutiger, Andreas (1983). Les commissions extra-parlementaires de la Confédération en 
REDES- Revista hispana para el análisis de redes sociales Vol.21,\#10, Diciembre 2011

http://revista-redes.rediris.es

1978. Tableaux statistiques. Lausanne: Cahiers de I'IDHEP, n॰9.

Gees, Thomas (1999). Interessenclearing und innere Absicherung. Zur Zusammenarbeit zwischen Verwaltung und Privatverbänden in der schweizerischen Aussenwirtschaftspolitik 1930-1960. In Hug, Peter y Martin Kloter (dir.), Aufstieg und Niedergang des Bilateralismus. Schweizerische Aussen- und Aussenwirtschaftspolitik 1930-1960: Rahmenbedingungen, Entscheidungsstrukturen, Fallstudien. Zurich, Lausanne: Chronos, Payot, 141-172.

Germann, Raimund E. (1981). Ausserparlamentarische Kommissionen: die Milizverwaltung des Bundes. Bern Stuttgart: Haupt.

Germann, Raimund E. (1987). L'amalgame public-privé l'administration para-étatique en Suisse. Lausanne: Institut de Hautes Etudes en Administration Publique.

Germann, Raimund E. (1996). Administration publique en Suisse. Berne etc.: Haupt.

Germann, Raimund E. (2005). Commissions extra-parlementaires. Dictionnaire historique de la Suisse (DHS), versión del 03.08.2005 (traducido del alemán), url: http://www.hlsdhs-dss.ch/textes/f/F10393.php

Germann, Raimund E. y Andreas Frutiger (1978). Les experts et la politique. Revue suisse de sociologie 2, 99-127.

Germann, Raimund E., et alter (1985). Experts et commissions de la Confédération. Lausanne: Presses Polytechniques Romandes.

Guex, Sébastien (2003). La politique de la Banque nationale suisse (1907-1939) : modèles, références et spécificités. In Feiertag, Oilivier y Michel Margairaz (dir.), Politiques et pratiques des banques d'émission en Europe (XVIIe-XXe siècle). Paris: Albin Michel, 526-548.

Hall, Peter y David Soskice (2001). An Introduction to Varieties of Capitalism. In Hall, Peter y David Soskice (dir.), Varieties of Capitalism: the Institutional Foundations of Comparative Advantage. Oxford: Oxford University Press, 1-68.

Hanneman, Robert A. y Mark Riddle (2005). Introduction to social network methods. Riverside, CA, University of California.

Hug, Peter (1998). Innenansichten der Aussenpolitik - Akteure und Interessen. In Studer, Brigitte (dir.), Etappen des Bundesstaates. Staats- und Nationsbildung der Schweiz, 1848-1998. Zurich: Chronos, 203-236.

Humair, Cédric (2004). Développement économique et Etat central (1815-1914). Un siècle de politique douanière au service des élites. Berne (etc.): Peter Lang. 
REDES- Revista hispana para el análisis de redes sociales Vol.21,\#10, Diciembre 2011

http://revista-redes.rediris.es

Jost, Hans Ulrich (1999). Le salaire des neutres. Suisse 1938-1948. Paris: Denoël.

Katzenstein, Peter (1985). Small states in world markets : industrial policy in Europe. Ithaca/London: Cornell University Press.

Knoke, David y James H. Kuklinski (1993). Network analysis. Newbury Park ; London [etc.]: Sage.

Kocher, Gerhard (1967). Verbandseinfluss auf die Gesetzgebung. Bern: A. Francke.

Kriesi, Hanspeter (2006). Institutional Filters and Path Dependency. The Impact of Europeanisation on Swiss Business Associations. In Streeck, Wolfgang et alter (dir.), Governing Interests. Business Associations Facing Internationalization. London, New York: Routledge, 49-65.

Krügle, Viktor (1962). Possibilités et limites d'une politique conjoncturelle active en Suisse. Neuchâtel: Université de Neuchâtel, Thèse de Doctorat.

Lanzalaco, Luca (2008). Business Interest Associations. In Jones, Geoffrey y Jonathan Zeitlin (dir.), Oxford Handbook of Business History. Oxford: Oxford University Press, 293318.

Leimgruber, Matthieu (2008). Solidarity without the State? : business and the shaping of the Swiss welfare state, 1890-2000. Cambridge: Cambridge University Press.

Mach, André (2006a). Interest groups. In Klöti, Ulrich et alter (dir.), Handbook of Swiss politic. Zurich: NZZ, 359-380.

Mach, André (2006b). La Suisse entre internationalisation et changements politiques internes : la législation sur les cartels et les relations industrielles dans les années 1990. Zurich: Rüegger.

Morandi, Pietro (2005). Démocratie de concordance. Dictionnaire historique de la Suisse (DHS), versión del 22.08.2005 (traducido del alemán), url: http://www.hls-dhsdss.ch/textes/f/F10095.php

Neidhart, Leonhard (1970). Plebiszit und pluralitäre Demokratie : eine Analyse der Funktion des schweizerischen Gesetzesreferendums Bern: Francke.

Oesch, Daniel (2007). Weniger Koordination, mehr Markt? Kollektive Arbeitsbeziehungen und Neokorporatismus in der Schweiz seit 1990. Swiss Political Science Review 13(3), 337-368.

Oesch, Daniel (2011). Swiss trade unions and industrial relations after 1990: a history of decline and renewal. In Mach, André y Christine Trampusch (dir.), Switzerland in Europe. Continuity and Change in the Swiss Political Economy. London: Routledge. 
REDES- Revista hispana para el análisis de redes sociales Vol.21,\#10, Diciembre 2011

http://revista-redes.rediris.es

OPCA, Organe parlementaire de contrôle de l'administration (1994). Fonction et influence des commissions extra-parlementaires de la Confédération. Rapport final à l'intention des Commissions de gestion des Chambres fédérales, Bern.

Pavillon, Sophie (2001). Les affinités économiques et le bon usage du diagnostic conjoncturel en Suisse, 1932-1947. Traverse 2, 110-123.

Pilotti, Andrea, André Mach y Oscar Mazzoleni (2010). Les parlementaires suisses entre démocratisation et professionnalisation, 1910-2000. Swiss Political Science Review $16(2), 211-245$.

Rebmann, Frédéric y Stéphanie Ginalski (2010). Le rôle du Vorort dans le processus de législation sur les cartels (1950-1962). In Cortat, Alain (dir.), Contribution à une histoire des cartels en Suisse. Neuchâtel: Alphil, 27-44.

Rebmann, Frédéric y André Mach (2012, pendiente de publicacióm). Les commissions extra-parlementaires. In Ladner, Andreas (dir.), Handbuch der öffentlichen Verwaltung in der Schweiz.

Rubattel, Rodolphe (1957). Les relations Confédération - groupements intéressés : étude présentée au Conseil fédéral. Berne: Feuille officielle suisse du commerce.

Rüegg, Erwin (1992). Die "Milizverwaltung des Bundes: Politikgestaltung durch Interessenten?" In Abromeit, Heidrun y Werner W. Pommerehne (dir.), Staatstätigkeit in der Schweiz. Bern ; Stuttgart [etc.]: P. Haupt, 97-119.

Sägesser, Thomas (2006). Die Überprüfung der ausserparlamentarischen Kommissionen im Rahmen der Bundesverwaltungsreform. EPA-Letter Public Management 2.

Sägesser, Thomas (2007). Regierungs- und Verwaltungsorganisationsgesetz (RVOG), vom 21. März 1997. Bern: Stämpfli Verlag AG.

Scharpf, Fritz (1991). La sociale-démocratie européenne face à la crise. Paris: Economica.

Schmid, Hanspeter (1983). Wirtschaft, Staat und Macht die Politik der schweizerischen Exportindustrie im Zeichen von Staats- und Wirtschaftskrise (1918-1929). Zürich: Limmat-Verlag.

Schnyder, Gerhard, Martin Lüpold, André Mach y Thomas David (2005). The rise and decline of the Swiss company network during the 20th Century. Université de Lausanne, Travaux de science politique 22. 
REDES- Revista hispana para el análisis de redes sociales Vol.21,\#10, Diciembre 2011

http://revista-redes.rediris.es

Schröter, Harm G. (1999). Small European Nations: Cooperative Capitalism in the Twentieth Century. In Chandler, Alfred D., Franco Amatori y Takashi Hikino (dir.), Big Business and the Wealth of Nations. Cambridge: Cambridge University Press, 176-204.

Sciarini, Pascal, Sarah Nicolet y Alex Fischer (2002). L'impact de l'internationalisation sur les processus de décision en Suisse: Une analyse quantitative des actes législatifs 19951999. Swiss Political Science Review 8(3/4), 1-34.

Sciarini, Pascal y Madeleine von Holzen (1995). GATT - Europe : la Suisse face à ses paysans. Genève: Georg; Journal de Genève et Gazette de Lausanne.

Streeck, Wolfgang (2006). The Study of Organized Interests: Before "the century" and after. In Crouch, Colin y Wolfgang Streeck (dir.), The Diversity of Democracy: Corporatism, social order and political conflic. London: Edward Elgar, 3-45.

Werner, Christian (2000). Für Wirtschaft und Vaterland Erneuerungsbewegungen und bürgerliche Interessengruppen in der Deutschschweiz, 1928-1947. Zürich: Chronos.

Windolf, Paul (2005). The Emergence of Corporate Networks in Germany and the United States 1896-1938 (working paper). (Publicado bajo el título: "Unternehmensverflechtung im organisierten Kapitalismus : Deutschland und die USA im Vergleich 1896-1938", Zeitschrift für Unternehmensgeschichte 2/2006 (51): 191-222). 


\section{Annexe 1: Représentation du réseau des commissions}

1910

\section{0}

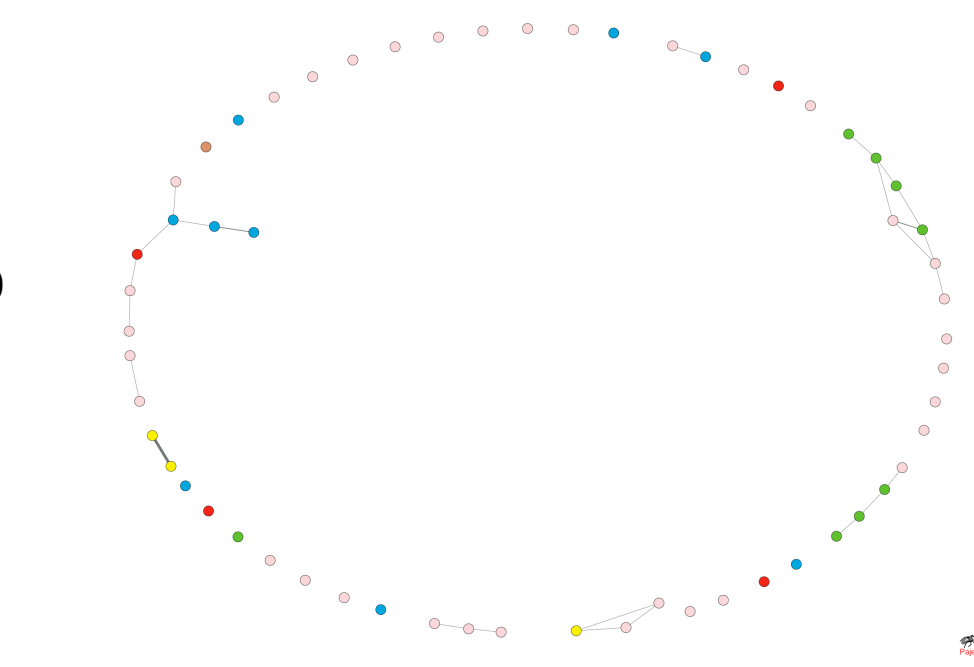

1937

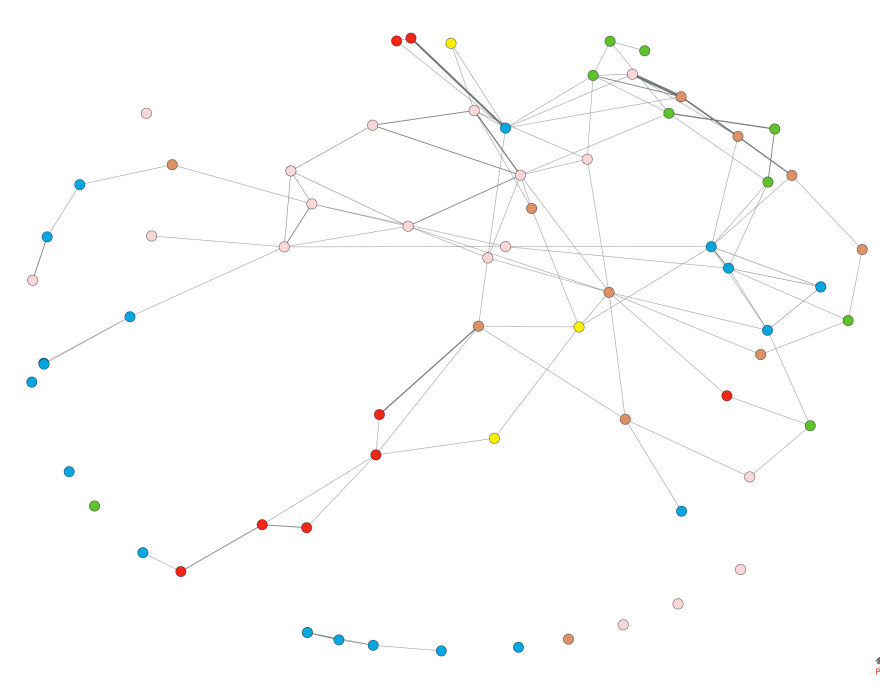

2000

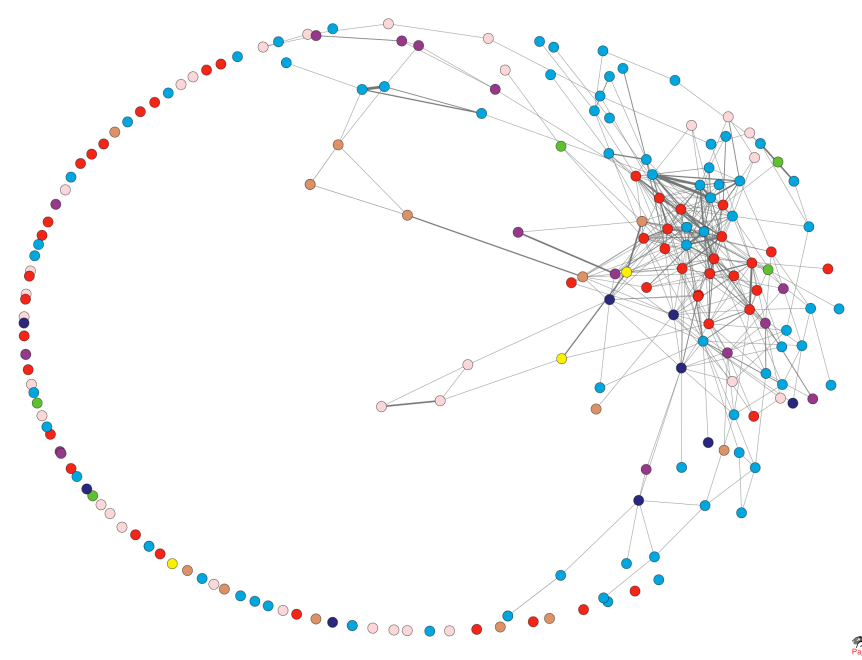

Notes :

1. La représentation du réseau est générée avec l'algorithme de dessin Fruchterman Reingold, facteur 1,5.

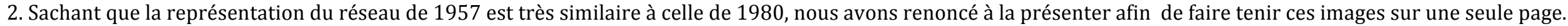

3. Les points, qui représentent les commissions, sont de couleurs différentes selon leur ancrage départemental. Jaune : Banque nationale suisse ; Vert : Département

militaire ; Mauve : Département des transports et de l'énergie ; Bleu foncé : Département des affaires étrangères ; Rouge : Département de l'économie ; Brun clair :

Département des finances ; Bleu clair : Département de l'intérieur ; Violet : Département de justice et police 
$\underline{\text { Commissions }}$

\begin{tabular}{|c|c|c|c|c|}
\hline & 1937 & 1957 & 1980 & 2000 \\
\hline \multicolumn{5}{|l|}{ Politique économique avec: } \\
\hline Politique commerciale & 0.222 & 0.119 & 0.133 & 0.083 \\
\hline Poltique agricole & 0.000 & 0.102 & 0.063 & 0.012 \\
\hline Politique du travail & 0.000 & 0.156 & 0.227 & 0.100 \\
\hline Assurance sociales & 0.167 & 0.126 & 0.114 & 0.118 \\
\hline Politique douanière & 0.000 & 0.056 & 0.009 & 0.133 \\
\hline Politique monétaire & 0.000 & 0.319 & 0.159 & 0.156 \\
\hline Politique financière & 0.083 & 0.093 & 0.045 & 0.000 \\
\hline \multicolumn{5}{|l|}{ Politique commerciale avec: } \\
\hline Politique agricole & 0.000 & 0.068 & 0.076 & 0.029 \\
\hline Politique du travail & 0.000 & 0.036 & 0.143 & 0.000 \\
\hline Assurance sociales & 0.000 & 0.083 & 0.089 & 0.077 \\
\hline Politique douanière & 0.667 & 0.229 & 0.200 & 0.375 \\
\hline Politique monétaire & 0.111 & 0.107 & 0.167 & 0.083 \\
\hline Politique financière & 0.000 & 0.071 & 0.060 & 0.000 \\
\hline \multicolumn{5}{|l|}{ Politique agricole avec: } \\
\hline Politique du travail & 0.000 & 0.037 & 0.081 & 0.000 \\
\hline Politique douanière & 0.000 & 0.053 & 0.026 & 0.059 \\
\hline Assurances sociales & 0.000 & 0.028 & 0.037 & 0.018 \\
\hline Politique monétaire & 0.000 & 0.092 & 0.087 & 0.020 \\
\hline Politique financière & 0.000 & 0.044 & 0.031 & 0.000 \\
\hline \multicolumn{5}{|l|}{ Politique du travail avec: } \\
\hline Politique douanière & 0.000 & 0.020 & 0.000 & 0.250 \\
\hline Assurances sociales & 0.333 & 0.095 & 0.276 & 0.096 \\
\hline Politique monétaire & 0.000 & 0.100 & 0.143 & 0.000 \\
\hline Politique financière & 0.083 & 0.033 & 0.143 & 0.000 \\
\hline \multicolumn{5}{|l|}{ Assurances sociales avec: } \\
\hline Politique monétaire & 0.083 & 0.105 & 0.143 & 0.077 \\
\hline Politique douanière & 0.250 & 0.126 & 0.029 & 0.000 \\
\hline Politique financière & 0.250 & 0.061 & 0.102 & 0.038 \\
\hline \multicolumn{5}{|l|}{ Politique financière avec: } \\
\hline Politique monétaire & 0.000 & 0.042 & 0.071 & 0.000 \\
\hline Politique douanière & 0.250 & 0.133 & 0.171 & 0.125 \\
\hline \multicolumn{5}{|l|}{ Politique douanière avec: } \\
\hline Politique monétaire & 0.333 & 0.050 & 0.050 & 0.000 \\
\hline
\end{tabular}

$\underline{\text { Acteurs }}$

\begin{tabular}{|c|c|c|c|c|}
\hline & 1937 & 1957 & 1980 & 2000 \\
\hline \multicolumn{5}{|l|}{ Associations patronales avec: } \\
\hline Syndicats ouvriers & 0.119 & 0.051 & 0.036 & 0.068 \\
\hline Associations de paysans & 0.000 & 0.041 & 0.017 & 0.091 \\
\hline Entreprises & 0.000 & 0.018 & 0.010 & 0.017 \\
\hline Autorités fédérales & 0.010 & 0.024 & 0.012 & 0.040 \\
\hline Autorités cantonales & 0.042 & 0.016 & 0.018 & 0.021 \\
\hline Milieux scientifiques & 0.000 & 0.014 & 0.008 & 0.013 \\
\hline \multicolumn{5}{|l|}{ Syndicats ouvriers avec: } \\
\hline Associations de paysans & 0.000 & 0.050 & 0.023 & 0.083 \\
\hline Entreprises & 0.143 & 0.029 & 0.020 & 0.008 \\
\hline Autorités fédérales & 0.054 & 0.021 & 0.017 & 0.020 \\
\hline Aurorités cantonales & 0.000 & 0.013 & 0.023 & 0.005 \\
\hline Milieux scientifiques & 0.000 & 0.017 & 0.008 & 0.029 \\
\hline \multicolumn{5}{|l|}{ Associations de paysans avec: } \\
\hline Entreprises & 0.000 & 0.016 & 0.016 & 0.000 \\
\hline Aurorités fédérales & 0.000 & 0.015 & 0.005 & 0.029 \\
\hline Aurorités cantonales & 0.000 & 0.018 & 0.013 & 0.000 \\
\hline Milieux scientifiques & 0.333 & 0.003 & 0.004 & 0.048 \\
\hline \multicolumn{5}{|l|}{ Autorités fédérales avec: } \\
\hline Autorités cantonales & 0.016 & 0.014 & 0.014 & 0.020 \\
\hline Entreprises & 0.109 & 0.005 & 0.008 & 0.020 \\
\hline Milieux scientifiques & 0.000 & 0.014 & 0.009 & 0.025 \\
\hline \multicolumn{5}{|l|}{ Autorités cantonales avec: } \\
\hline Entreprises & 0.000 & 0.004 & 0.013 & 0.056 \\
\hline Milieux scientifiques & 0.000 & 0.002 & 0.010 & 0.013 \\
\hline \multicolumn{5}{|l|}{ Milieux scientifiques avec: } \\
\hline Entreprises & 0.167 & 0.006 & 0.007 & 0.022 \\
\hline
\end{tabular}

Notes :

1. Les densités exogamiques nulles sont surlignées en jaune

2. Les trois densités exogamiques les plus élevées au niveau des acteurs sont surlignées en rouge 


\section{Annexe 3: Tables de densité endo et exogamiques selon l' affiliation des acteurs}

\begin{tabular}{|l|c|c|c|c|c|c|c|}
\hline \multicolumn{1}{|c|}{1910} & 1 & 2 & 3 & 4 & $\varnothing$ Inter & $\varnothing \mathrm{Gen}$ & $\mathrm{N}$ \\
\hline 1. Entreprises & 0.667 & 0.833 & 0.278 & 0.167 & 0.426 & 0.486 & 6 \\
\hline 2. Autorités cantonales et communales & 0.833 & & 0.333 & 0.000 & 0.389 & 0.389 & 1 \\
\hline 3. Autorités fédérales & 0.278 & 0.333 & 0.333 & 0.000 & 0.204 & 0.236 & 3 \\
\hline 4. Divers & 0.167 & 0.000 & 0.000 & & 0.056 & 0.056 & 1 \\
\hline$\varnothing$ Inter & 0.426 & 0.389 & 0.204 & 0.056 & & & \\
\hline$\varnothing$ Gen & 0.486 & 0.389 & 0.236 & 0.056 & & & \\
\hline $\mathrm{N}$ & 6 & 1 & 3 & 1 & & & \\
\hline
\end{tabular}

\section{Notes :}

1. $\emptyset$ Inter = densité moyenne exogamique $; \varnothing \mathrm{Gen}=$ densité moyenne générale $; \mathrm{N}=$ nombre de commissions. Ces remarques sont valables pour les cinq tableaux

2. Probabilité de Variable homophily $=0.922(>0.05)$ : résultats non significatifs :

Probabilité de Structural blockmodel $=0.824(>0.05)$ : résultats non significatifs.

\begin{tabular}{|l|c|c|c|c|c|c|c|c|cc|c|}
\hline \multicolumn{1}{|c|}{1957} & 1 & 2 & 3 & 4 & 5 & 6 & 7 & 8 & $\varnothing$ Inter & $\varnothing$ Gen & $\mathrm{N}$ \\
\hline 1. Associations patronales & 0.031 & 0.051 & 0.041 & 0.024 & 0.018 & 0.034 & 0.016 & 0.014 & 0.028 & 0.029 & 50 \\
2. Syndicats ouvriers & 0.051 & 0.068 & 0.050 & 0.021 & 0.029 & 0.010 & 0.013 & 0.017 & 0.027 & 0.032 & 27 \\
3. Associations de paysans & 0.041 & 0.050 & 0.058 & 0.015 & 0.016 & 0.011 & 0.018 & 0.003 & 0.022 & 0.026 & 20 \\
4. Autorités fédérales & 0.024 & 0.021 & 0.015 & 0.030 & 0.005 & 0.010 & 0.014 & 0.014 & 0.015 & 0.016 & 56 \\
5. Entreprises & 0.018 & 0.029 & 0.016 & 0.005 & 0.023 & 0.009 & 0.004 & 0.006 & 0.013 & 0.014 & 38 \\
6. Divers & 0.034 & 0.010 & 0.011 & 0.010 & 0.009 & 0.059 & 0.006 & 0.003 & 0.012 & 0.018 & 23 \\
7. Autorités cantonales et communales & 0.016 & 0.013 & 0.018 & 0.014 & 0.004 & 0.006 & 0.050 & 0.002 & 0.010 & 0.015 & 34 \\
8. Milieux scientifiques & 0.014 & 0.017 & 0.003 & 0.014 & 0.006 & 0.003 & 0.002 & 0.055 & 0.008 & 0.014 & 33 \\
\hline$\varnothing$ Inter & 0.028 & 0.027 & 0.022 & 0.015 & 0.013 & 0.012 & 0.010 & 0.008 & & & \\
\hline$\varnothing$ Gen & 0.029 & 0.032 & 0.026 & 0.016 & 0.014 & 0.018 & 0.015 & 0.014 & & & \\
\hline $\mathrm{N}$ & 50 & 27 & 20 & 56 & 38 & 23 & 34 & 33 & & & \\
\hline
\end{tabular}

Note : Probabilité de Variable homophily $=0.000(<0.05)$ : résultats significatifs :

Probabilité de Structural blockmodel $=0.000(<0.05)$ : résultats significatifs

\begin{tabular}{|l|c|c|c|c|c|c|c|c|c|c|c|}
\hline \multicolumn{1}{|c|}{1937} & 1 & 2 & 3 & 4 & 5 & 6 & 7 & 8 & $\varnothing$ Inter & $\varnothing \mathrm{Gen}$ & $\mathrm{N}$ \\
\hline 1. Milieux scientifiques & 0.333 & 0.167 & 0.333 & 0.000 & 0.000 & 0.000 & 0.000 & 0.000 & 0.071 & 0.104 & 3 \\
2. Entreprises & 0.167 & 0.333 & 0.000 & 0.143 & 0.000 & 0.109 & 0.063 & 0.000 & 0.069 & 0.102 & 4 \\
3. Associations de paysans & 0.333 & 0.000 & & 0.000 & 0.000 & 0.000 & 0.000 & 0.000 & 0.048 & 0.048 & 1 \\
4. Syndicats ouvriers & 0.000 & 0.143 & 0.000 & 0.333 & 0.119 & 0.054 & 0.000 & 0.000 & 0.045 & 0.081 & 7 \\
5. Associations patronales & 0.000 & 0.00 & 0.000 & 0.119 & 0.067 & 0.010 & 0.083 & 0.042 & 0.036 & 0.040 & 6 \\
6. Autorités fédérales & 0.000 & 0.109 & 0.000 & 0.054 & 0.010 & 0.142 & 0.000 & 0.016 & 0.027 & 0.041 & 16 \\
7. Divers & 0.000 & 0.063 & 0.000 & 0.000 & 0.083 & 0.000 & 0.167 & 0.000 & 0.021 & 0.039 & 4 \\
8. Autorités cantonales et communales & 0.000 & 0.000 & 0.000 & 0.000 & 0.042 & 0.016 & 0.000 & 0.167 & 0.008 & 0.028 & 4 \\
\hline$\varnothing$ Inter & 0.071 & 0.069 & 0.048 & 0.045 & 0.036 & 0.027 & 0.021 & 0.008 & & & \\
$\varnothing$ Gen & 0.104 & 0.102 & 0.048 & 0.081 & 0.040 & 0.041 & 0.039 & 0.028 & & \\
$\mathrm{~N}$ & 3 & 4 & 1 & 7 & 6 & 16 & 4 & 4 & & \\
\hline
\end{tabular}

Note : Probabilité de Variable homophily $=0.919(>0.05)$ : résultats non significatifs ;

Probabilité de Structural blockmodel $=0.844(>0.05)$ : résultats non significatifs

\begin{tabular}{|l|c|c|c|c|c|c|c|c|c|c|c|}
\hline \multicolumn{1}{|c|}{1980} & 1 & 2 & 3 & 4 & 5 & 6 & 7 & 8 & $\varnothing$ Inter & $\varnothing \mathrm{Gen}$ & $\mathrm{N}$ \\
\hline 1. Syndicats ouvriers & 0.060 & 0.036 & 0.023 & 0.023 & 0.020 & 0.017 & 0.021 & 0.008 & 0.021 & 0.026 & 32 \\
2. Associations patronales & 0.036 & 0.028 & 0.018 & 0.017 & 0.010 & 0.012 & 0.015 & 0.008 & 0.017 & 0.018 & 43 \\
3. Autorités cantonales et communales & 0.023 & 0.018 & 0.022 & 0.013 & 0.013 & 0.014 & 0.011 & 0.010 & 0.015 & 0.016 & 44 \\
4. Associations de paysans & 0.023 & 0.017 & 0.013 & 0.040 & 0.016 & 0.005 & 0.005 & 0.004 & 0.012 & 0.015 & 24 \\
\hline 5. Entreprises & 0.020 & 0.010 & 0.013 & 0.016 & 0.018 & 0.008 & 0.008 & 0.007 & 0.012 & 0.013 & 57 \\
6. Autorités fédérales & 0.017 & 0.012 & 0.014 & 0.005 & 0.008 & 0.021 & 0.008 & 0.009 & 0.010 & 0.012 & 74 \\
7. Divers & 0.021 & 0.015 & 0.011 & 0.005 & 0.008 & 0.008 & 0.014 & 0.003 & 0.010 & 0.011 & 32 \\
8. Milieux scientifiques & 0.008 & 0.008 & 0.010 & 0.004 & 0.007 & 0.009 & 0.003 & 0.019 & 0.007 & 0.009 & 47 \\
\hline$\varnothing$ Inter & 0.021 & 0.017 & 0.015 & 0.012 & 0.012 & 0.010 & 0.010 & 0.007 & & & \\
\hline$\varnothing$ Gen & 0.026 & 0.018 & 0.016 & 0.015 & 0.013 & 0.012 & 0.011 & 0.009 & & & \\
\hline$N$ & 32 & 43 & 44 & 24 & 57 & 74 & 32 & 47 & & & \\
\hline
\end{tabular}

Note : Probabilité de Variable homophily $=0.001(<0.05)$ : résultats significatifs ; Probabilité de Structural blockmodel $=0.002(<0.05)$ : résultats significatifs

\begin{tabular}{|c|c|c|c|c|c|c|c|c|c|c|c|}
\hline 2000 & 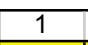 & 2 & 3 & 4 & 5 & 6 & 7 & 8 & $\varnothing$ Inter & $\varnothing \mathrm{Gen}$ & $\mathrm{N}$ \\
\hline 1. Associations patronales & 0.052 & 0.091 & 0.068 & 0.040 & 0.017 & 0.013 & 0.025 & 0.021 & 0.039 & 0.041 & 22 \\
\hline s de pay & 0.091 & 0.000 & 0.083 & 0.029 & 0.000 & 0.048 & 0.000 & 0.000 & 0.036 & 0.031 & 3 \\
\hline ouvriers & 0.068 & 0.083 & 0.074 & 0.020 & 0.008 & 0.029 & 0.027 & 0.005 & 0.034 & 0.039 & 20 \\
\hline fédérales & 0.040 & 0.029 & 0.020 & 0.040 & 0.020 & 0.025 & 0.024 & 0.020 & 0.025 & 0.027 & 23 \\
\hline 5. En & 017 & 0.000 & 0.008 & 0.020 & 0.064 & 0.022 & 0.042 & 0.056 & 0.024 & 0.029 & 13 \\
\hline ques & 0.013 & 0.048 & 0.029 & 0.025 & 0.022 & 0.000 & 0.013 & 0.013 & 0.023 & 0.020 & 7 \\
\hline 7. D & 0.025 & 0.000 & 0.027 & 0.024 & 0.042 & 0.013 & 0.036 & 0.017 & 1 & 0.023 & 11 \\
\hline cantonales et con & 0.021 & 0.000 & 0.005 & 0.020 & 0.056 & 0.013 & 0.017 & 0.018 & 0.019 & 0.019 & 11 \\
\hline$\varnothing$ Inter & 0.039 & 0.036 & 0.034 & 0.025 & 0.024 & 0.023 & 0.021 & 0.019 & & & \\
\hline$\varnothing \mathrm{G}$ & 0.041 & 0.031 & 0.039 & 0.027 & 0.029 & 0.020 & 0.023 & 0.019 & & & \\
\hline & 22 & 3 & 20 & 23 & 13 & 7 & 11 & 11 & & & \\
\hline
\end{tabular}

Note : Probabilité de Variable homophily $=0.078(>0.05)$ : résultats non significatifs ;

Probabilité de Structural blockmodel $=0.020(<0.05)$ : résultats significatifs 


\section{Annexe 4: Tables de densité endo et exogamiques selon les politiques des commissions}

\begin{tabular}{|c|c|c|c|c|c|c|c|c|c|c|c|c|c|c|}
\hline 1910 & 1 & 2 & 3 & 4 & 5 & 6 & 7 & 8 & 9 & 10 & 11 & $\varnothing$ Inter & $\varnothing$ gen & $\mathrm{N}$ \\
\hline 01. Science & 0.333 & 0.333 & 0.000 & 0.000 & 0.167 & 0.000 & 0.011 & 0.056 & 0.000 & 0.000 & 0.000 & 0.057 & 0.082 & 3 \\
\hline 02. Energie & 0.333 & & 0.000 & 0.000 & 0.000 & 0.000 & 0.000 & 0.000 & 0.000 & 0.000 & 0.000 & 0.033 & 0.033 & 1 \\
\hline 03. Armée & 0.000 & 0.000 & 0.300 & 0.200 & 0.000 & 0.100 & 0.007 & 0.000 & 0.000 & 0.000 & 0.000 & 0.031 & 0.055 & 5 \\
\hline 04. Assurances sociales & 0.000 & 0.000 & 0.200 & & 0.000 & 0.000 & 0.000 & 0.000 & 0.000 & 0.000 & 0.000 & 0.020 & 0.020 & 1 \\
\hline 05. Agriculture & 0.167 & 0.000 & 0.000 & 0.000 & 0.000 & 0.000 & 0.017 & 0.000 & 0.000 & 0.000 & 0.000 & 0.018 & 0.017 & 2 \\
\hline 06. Transport & 0.000 & 0.000 & 0.100 & 0.000 & 0.000 & 0.167 & 0.025 & 0.000 & 0.000 & 0.000 & 0.000 & 0.013 & 0.027 & 4 \\
\hline 07. Territoire & 0.011 & 0.000 & 0.007 & 0.000 & 0.017 & 0.025 & 0.011 & 0.000 & 0.022 & 0.000 & 0.000 & 0.008 & 0.008 & 30 \\
\hline 08. Formation & 0.056 & 0.000 & 0.000 & 0.000 & 0.000 & 0.000 & 0.000 & 0.000 & 0.000 & 0.000 & 0.000 & 0.006 & 0.005 & 6 \\
\hline 09. Monétaire & 0.000 & 0.000 & 0.000 & 0.000 & 0.000 & 0.000 & 0.022 & 0.000 & 0.333 & 0.000 & 0.000 & 0.002 & 0.032 & 3 \\
\hline 10. Culture & 0.000 & 0.000 & 0.000 & 0.000 & 0.000 & 0.000 & 0.000 & 0.000 & 0.000 & 0.000 & 0.000 & 0.000 & 0.000 & 3 \\
\hline 11. Sanitaire & 0.000 & 0.000 & 0.000 & 0.000 & 0.000 & 0.000 & 0.000 & 0.000 & 0.000 & 0.000 & & 0.000 & 0.000 & 1 \\
\hline$\varnothing$ Inter & 0.057 & 0.033 & 0.031 & 0.020 & 0.018 & 0.013 & 0.008 & 0.006 & 0.002 & 0.000 & 0.000 & & & \\
\hline$\varnothing$ Gen & 0.082 & 0.033 & 0.055 & 0.020 & 0.017 & 0.027 & 0.008 & 0.005 & 0.032 & 0.000 & 0.000 & & & \\
\hline $\mathrm{N}$ & 3 & 1 & 5 & 1 & 2 & 4 & 30 & 6 & 3 & 3 & 1 & & & \\
\hline
\end{tabular}

Notes :

1. $\varnothing$ Inter = densité moyenne exogamique $\varnothing \emptyset \mathrm{Gen}=$ densité moyenne générale $; \mathrm{N}=$ nombre de commissions. Ces remarques sont valables pour les cinq tableaux.

2. Probabilité de Variable homophily $=0.088(>0.05)$ : résultats non significatifs ; Probabilité de Structural blockmodel $=0.919(>0.05)$ : résultats non significatifs

\begin{tabular}{|c|c|c|c|c|c|c|c|c|c|c|c|c|c|c|c|c|c|c|c|c|c|}
\hline 1937 & 1 & 2 & 3 & 4 & 5 & 6 & 7 & 8 & 9 & 10 & 11 & 12 & 13 & 14 & 15 & 16 & 17 & 18 & $\varnothing$ Inter & $\varnothing$ Gen & $\mathrm{N}$ \\
\hline ances sociales & .000 & 250 & 0.000 & 250 & 0.250 & .000 & .063 & 0.083 & $\overline{0.000}$ & 0.125 & .333 & 167 & $\overline{0}$ & 0.000 & 0.000 & 0.000 & $\overline{031}$ & 0.000 & 0.091 & 36 & $\overline{4}$ \\
\hline s & 250 & & 0.000 & 0.250 & 0.000 & 667 & 000 & 0.333 & 0.000 & .000 & .000 & 000 & 0 & 000 & 0.000 & 00 & .000 & 0 & 8 & & \\
\hline poids et mesures & 000 & 000 & 000 & $0 . \angle 50$ & 000 & 00 & 0 & 333 & 00 & 00 & 00 & 00 & & 0 & 0.067 & 0 & & & & & \\
\hline & 250 & $.250^{\circ}$ & 0.250 & 167 & 125 & 000 & 00 & 000 & 000 & 125 & 083 & 083 & 0 & .000 & 0.017 & 0 & 0 & 00 & 84 & 39 & 4 \\
\hline & 250 & 0.000 & 0.000 & .125 & 000 & 000 & 000 & 167 & 600 & 000 & 000 & 00 & & .000 & .067 & 00 & & .000 & 79 & & \\
\hline e comı & 000 & 667 & 0.000 & .000 & 0.000 & 333 & 250 & 0.111 & 0.000 & .000 & .000 & 222 & 00 & 0.000 & 0.022 & 0.000 & 00 & .000 & 075 & & \\
\hline$F_{t}$ & 063 & .000 & 0.500 & .000 & .000 & 250 & .500 & 0.083 & 0.000 & .125 & .000 & .000 & 36 & 0.000 & 0.100 & 0.000 & 00 & & & & \\
\hline e & 083 & 333 & 333 & 000 & 167 & 111 & 083 & 0.333 & 0.000 & 0.000 & 00 & 000 & & 0.000 & 0.000 & 0.000 & 00 & & & & \\
\hline & 0 & 000 & 100 & 000 & 0 & 0 & 0 & 0.0 & 0 & 0 & 0 & 0 & & 0 & 13 & 00 & 25 & & & & \\
\hline & 25 & 000 & 0.00 & 125 & 0 & & & & 0. & & & & & & & & & & & & \\
\hline $\mathrm{T}$ & 33 & 000 & 000 & 083 & 00 & 0 & 0 & 0.0 & 0.0 & 7 & 33 & .000 & & 00 & 0. & 0.000 & 0 & 0 & 34 & 51 & \\
\hline . $\mathrm{P}$ & 167 & 000 & 000 & 083 & 000 & 222 & 0 & 0.000 & 0.000 & .000 & 000 & 333 & 0 & 00 & 0.000 & 0 & & & & & \\
\hline $\mathrm{Ar}$ & 0.000 & 000 & .000 & 000 & 143 & 000 & 36 & 0.000 & 0.029 & 3 & 000 & .000 & 38 & 0.071 & 0.010 & 0.000 & 00 & 0 & & 37 & \\
\hline ure & 0.000 & .000 & 0.250 & .000 & .000 & 0.000 & .000 & 0.000 & 0.000 & 0.000 & 0 & 0 & 0.071 & 0.000 & 0.033 & 0. & 63 & 0 & & 23 & 2 \\
\hline & 000 & 000 & 0.067 & 017 & 067 & 22 & 0 & 0.000 & 0.013 & & & & & & 0.114 & 0.000 & 00 & & & & \\
\hline no & 000 & 000 & 0.000 & 250 & 00 & 0 & & & & & & & & & 0.000 & & & & & & \\
\hline & 31 & 00 & .000 & 0 & 0 & 0 & & 0 & 08 & & & & & & 0.000 & & 50 & 0 & & & \\
\hline & & & & & & & & & & & & & & & 0.000 & & & & 000 & .000 & \\
\hline Inter & 91 & 088 & 088 & 084 & 079 & 075 & 068 & 0.065 & 0.045 & .044 & 0.034 & 0.028 & 0.025 & 0.025 & 0.023 & 0.015 & 0.007 & 0.000 & & & \\
\hline$\varnothing$ Gen & 086 & .088 & 0.083 & .089 & .131 & 0.089 & .092 & 0.080 & 0.059 & 0.042 & 0.051 & 0.045 & 0.037 & 0.023 & 0.028 & .015 & .020 & .000 & & & \\
\hline & 4 & 1 & 2 & 4 & 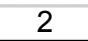 & 3 & 4 & 3 & 5 & 2 & 3 & 3 & 1 & & 15 & & & & & & \\
\hline
\end{tabular}

Note : Probabilité de Variable homophily = $0.985(>0.05)$ : résultats non significatifs ; Probabilité de Structural blockmodel $=0.000(<0.05):$ résultats significatifs 


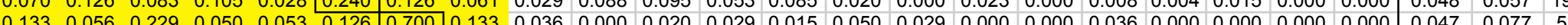

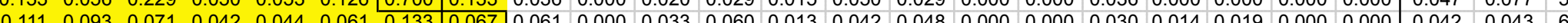

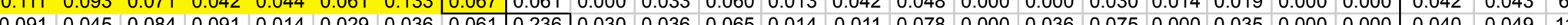

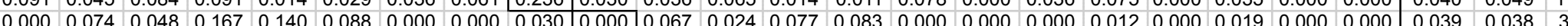

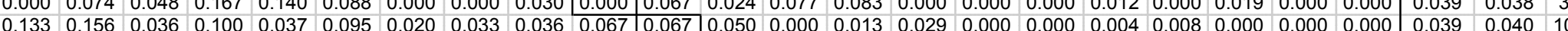

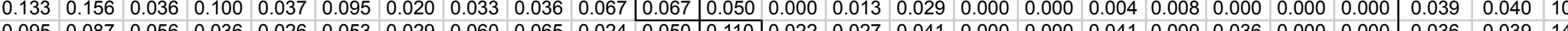

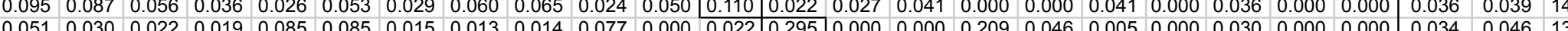

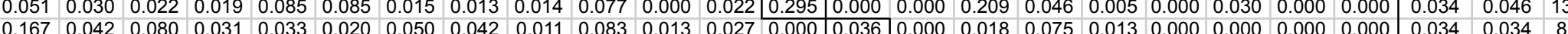

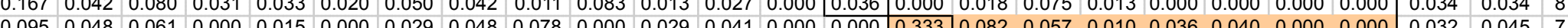

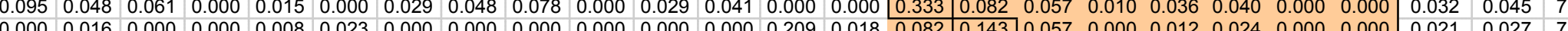

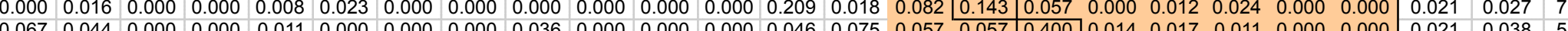

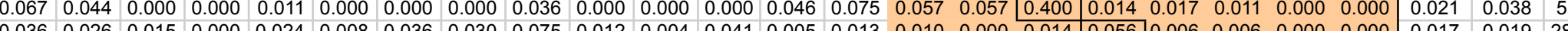

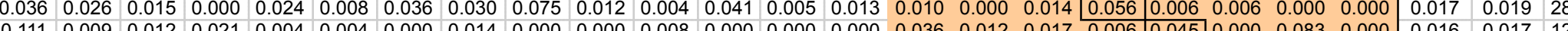

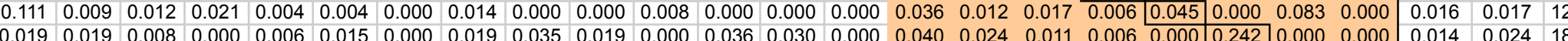

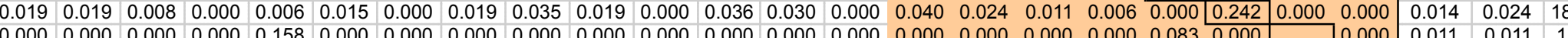

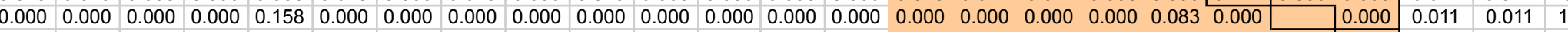

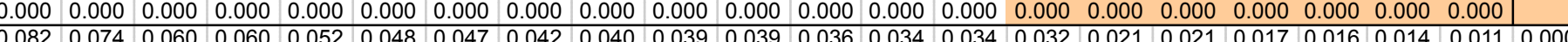

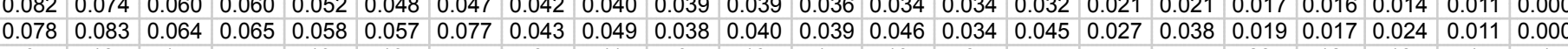

\begin{tabular}{|c|c|c|c|c|c|c|c|c|c|c|c|c|c|c|c|c|c|c|c|c|c|c|c|c|c|c|}
\hline 1980 & 1 & 2 & 3 & 4 & 5 & 6 & 7 & 8 & 9 & 10 & 11 & 12 & 13 & 14 & 15 & 16 & 17 & 18 & 19 & 20 & 21 & 22 & 23 & $\varnothing$ Inter & $\overline{\partial \mathrm{Gen}}$ & $\mathrm{N}$ \\
\hline 1. Travail & 667 & .143 & 0.143 & 0.143 & 0.276 & 0.227 & 0.082 & 0.000 & 0.143 & 0.089 & 0.024 & 0.081 & 0.087 & 0.060 & 0.076 & 0.000 & 0.071 & .120 & .143 & 0.015 & 0.027 & 0.026 & 0.000 & 0.090 & 0.115 & \\
\hline 02. Politique commerciale & 0.143 & 0.152 & 0.125 & 0.167 & 0.089 & 0.133 & 0.155 & 0.200 & 0.060 & 0.000 & 0.042 & 0.076 & 0.037 & 0.049 & 0.033 & 0.083 & 0.009 & 0.018 & 0.042 & 0.023 & 0.019 & 0.012 & 0.006 & 0.069 & 0.073 & 12 \\
\hline 03. Communication & 0.143 & 0.125 & 0.000 & 0.125 & 0.179 & 0.091 & 0.071 & 0.100 & 0.143 & 0.000 & 0.000 & 0.022 & 0.028 & 0.083 & 0.033 & 0.250 & 0.000 & 0.053 & 0.000 & 0.000 & 0.000 & 0.037 & 0.000 & 0.067 & 0.064 & 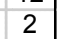 \\
\hline 04. Monétaire & 0.143 & 0.167 & 0.125 & 0.000 & 0.143 & 0.159 & 0.107 & 0.050 & 0.071 & 0.031 & 0.083 & 0.087 & 0.069 & 0.042 & 0.017 & 0.000 & 0.069 & 0.013 & 0.000 & 0.017 & 0.010 & 0.028 & 0.000 & 0.065 & 0.062 & 4 \\
\hline 05. Assurance & 0.276 & 0.089 & 0.179 & 0.143 & 0.231 & 0.114 & 0.031 & 0.029 & 0.102 & 0.018 & 0.060 & .037 & 0.036 & 0.012 & 0.014 & 0.000 & 0.028 & 0.049 & 0.071 & 0.007 & 0.044 & 0.029 & 0.016 & 0.063 & 0.070 & 14 \\
\hline 06. Politique é & 0.227 & 0.133 & 0.091 & 0.159 & 0.114 & 0.147 & 0.078 & 0.009 & 0.045 & 0.023 & 0.038 & .063 & 0.058 & 0.045 & 0.036 & 0.045 & 0.056 & 0.026 & 0.080 & 0.009 & 0.012 & 0.007 & 0.003 & 0.062 & 0.065 & 22 \\
\hline 07. Affaires ét & 0.082 & 0.155 & 0.071 & 0.107 & 0.031 & 0.078 & \begin{tabular}{|l|}
0.143 \\
\end{tabular} & 0.343 & 0.061 & 0.000 & 0.024 & 0.037 & 0.032 & 0.060 & 0.048 & 0.000 & 0.032 & 0.060 & 0.000 & 0.034 & 0.005 & 0.011 & 0.033 & 0.059 & 0.063 & 7 \\
\hline 08. Douanes & 0.000 & 0.200 & 0.100 & 0.050 & 0.029 & 0.009 & 0.343 & 0.600 & 0.171 & 0.000 & 0.000 & .026 & 0.011 & 0.017 & 0.000 & 0.000 & 0.000 & 0.000 & 0.000 & 0.055 & 0.000 & 0.000 & & 0.046 & & 5 \\
\hline 09. Finances & 0.143 & 0.060 & 0.143 & 0.071 & 0.102 & 0.045 & 0.061 & 0.171 & 0.095 & 0.000 & 0.048 & 0.031 & 0.000 & 0.012 & 0.010 & 0.071 & 0.000 & 0.008 & 0.000 & 0.005 & 0.005 & 0.005 & 0.000 & 0.045 & 0.047 & 7 \\
\hline 10. Environne & 0.089 & .000 & 0.000 & 0.031 & 0.018 & 0.023 & 0.000 & 0.000 & 0.000 & 0.500 & 0.125 & 0.005 & 0.056 & 0.031 & 0.033 & 0.000 & 0.076 & 0.013 & 0.000 & 0.121 & 0.048 & 0.005 & 0.019 & 0.032 & 52 & 8 \\
\hline 11. Normes & 0.024 & 0.042 & 0.000 & 0.083 & 0.060 & 0.038 & 0.024 & 0.000 & 0.048 & 0.125 & \begin{tabular}{|l|}
0.267 \\
\end{tabular} & 0.058 & 0.037 & 0.014 & 0.022 & 0.000 & 0.009 & 0.018 & 0.000 & 0.011 & 0.032 & 0.031 & 0.000 & 0.031 & 0.041 & 6 \\
\hline 12. Agriculture & 0.081 & 0.076 & 0.022 & 0.087 & 0.037 & 0.063 & 0.037 & 0.026 & 0.031 & .005 & 0.058 & 0.154 & 0.005 & 0.014 & 0.012 & 0.000 & 0.029 & 0.002 & 0.022 & 0.015 & 0.023 & 0.006 & 0.010 & 0.030 & 0.036 & 23 \\
\hline 13. Transport & 0.087 & 0.037 & 0.028 & 0.069 & 0.036 & 0.058 & 0.032 & 0.011 & 0.000 & 0.056 & 0.037 & 0.005 & 0.170 & 0.028 & 0.030 & 0.028 & 0.025 & 0.012 & 0.014 & 0.036 & 0.011 & 0.014 & 0.000 & 0.030 & 0.036 & 18 \\
\hline 14. Divers & 0.060 & 0.049 & 0.083 & 0.042 & 0.012 & 0.045 & 0.060 & 0.017 & 0.012 & 0.031 & 0.014 & 0.014 & 0.028 & 0.000 & 0.017 & 0.042 & 0.014 & 0.013 & 0.021 & 0.000 & 0.016 & 0.009 & 0.013 & 0.028 & 0.027 & 12 \\
\hline 15. Science & 0.076 & 0.033 & 0.033 & 0.017 & 0.014 & 0.036 & 0.048 & 0.000 & 0.010 & 0.033 & 0.022 & 0.012 & 0.030 & 0.017 & 0.229 & 0.000 & 0.037 & 0.035 & 0.050 & 0.011 & 0.015 & 0.044 & 0.031 & 0.027 & 0.036 & 15 \\
\hline 16. Justice & 0.000 & 0.083 & 0.250 & 0.000 & 0.000 & 0.045 & 0.000 & 0.000 & 0.071 & 0.000 & 0.000 & 0.000 & 0.028 & 0.042 & 0.000 & 0.000 & 0.000 & 0.000 & 0.000 & 0.000 & 0.000 & 0.000 & 0.000 & 0.024 & 0.023 & 2 \\
\hline 17. Er & 0.071 & 0.009 & 0.000 & 0.069 & 0.028 & 0.056 & 0.032 & 0.000 & 0.000 & 0.076 & 0.009 & 0.029 & 0.025 & 0.014 & 0.037 & 0.000 & 0.092 & 0.003 & 0.014 & 0.023 & 0.013 & 0.004 & 0.004 & 0.023 & 26 & 18 \\
\hline 18. Formation & 0.120 & 0.018 & 0.053 & 0.013 & 0.049 & 0.026 & 0.060 & 0.000 & 0.008 & 0.013 & 0.018 & 0.002 & 0.012 & 0.013 & 0.035 & 0.000 & 0.003 & 0.111 & 0.013 & 0.004 & 0.034 & 0.004 & 0.008 & 0.023 & 0.027 & 19 \\
\hline 19. Cito & 0.143 & 0.042 & 0.000 & 0.000 & 0.071 & 0.080 & 0.000 & 0.000 & 0.000 & 0.000 & 0.000 & 0.022 & 0.014 & 0.021 & 0.050 & 0.000 & 0.014 & 0.013 & 0.167 & 0.017 & 0.000 & 0.000 & 0.019 & 0.023 & 29 & 4 \\
\hline 20. Terri & 0.015 & 0.023 & 0.000 & 0.017 & 0.007 & 0.009 & 0.034 & 0.055 & 0.005 & 0.121 & 0.011 & 0.015 & 0.036 & 0.000 & 0.011 & 0.000 & 0.023 & 0.004 & 0.017 & 0.069 & 0.008 & 0.004 & 0.003 & 0.019 & 0.021 & 29 \\
\hline 21. Sanitaire & 0.027 & 0.019 & 0.000 & 0.010 & 0.044 & 0.012 & 0.005 & 0.000 & 0.005 & 0.048 & 0.032 & 0.023 & 0.011 & 0.016 & 0.015 & 0.000 & 0.013 & 0.034 & 0.000 & 0.008 & 0.132 & 0.016 & 0.003 & 0.016 & 0.021 & 26 \\
\hline 22. Armée & 0.026 & 0.012 & 0.037 & 0.028 & 0.029 & 0.007 & 0.011 & 0.000 & 0.005 & 005 & 0.031 & 0.006 & 0.014 & 0.009 & 0.044 & 0.000 & 0.004 & 0.004 & 0.000 & 0.004 & 0.016 & 0.085 & 0.014 & 0.014 & 0.017 & 27 \\
\hline 23. Culture & 0.000 & 0.006 & 0.000 & 0.000 & 0.016 & 0.003 & 0.033 & 0.000 & 0.000 & .019 & 0.000 & 0.010 & 0.000 & 0.013 & 0.031 & 0.000 & 0.004 & 0.008 & 0.019 & 0.003 & 0.003 & 0.014 & 0.103 & 0.008 & 0.012 & 13 \\
\hline Inter & 0.090 & 0.069 & 0.067 & 0.065 & 0.063 & 0.062 & 0.059 & 0.046 & 0.045 & .032 & 0.031 & 0.030 & 0.030 & 0.028 & 0.027 & 0.024 & 0.023 & 0.023 & 0.023 & 0.019 & 0.016 & 0.014 & 0.008 & & & \\
\hline$\gamma$ Gen & 0.115 & 0.073 & 0.064 & 0.062 & 0.070 & 0.065 & 0.063 & 0.070 & 0.047 & 0.052 & 0.041 & 0.036 & 0.036 & 0.027 & 0.036 & 0.023 & 0.026 & 0.027 & 0.029 & 0.021 & 0.021 & 0.017 & 0.012 & & & \\
\hline & 7 & 12 & 2 & 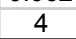 & 14 & 22 & 7 & 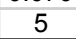 & 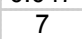 & 0 & 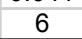 & 23 & 18 & 12 & 15 & 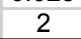 & 18 & 19 & 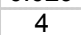 & 29 & 26 & 27 & 13 & & & \\
\hline
\end{tabular}

Note : Probabilité de Variable homophily $=0.000(<0.05)$ : résultats significatifs ; Probabilité de Structural blockmodel $=0.000(<0.05):$ résultats significatifs 


\begin{tabular}{|c|c|c|c|c|c|c|c|c|c|c|c|c|c|c|c|c|c|c|c|c|c|c|c|c|}
\hline 2000 & 1 & 2 & 3 & 4 & 5 & 6 & 7 & 8 & 9 & 10 & 11 & 12 & 13 & 14 & 15 & 16 & 17 & 18 & 19 & 20 & 21 & $\varnothing$ Inter & $\varnothing$ Gen & $\mathrm{N}$ \\
\hline 01. Douanes & 0.000 & 0.375 & 0.133 & 0.250 & 0.000 & 0.143 & 0.000 & 0.143 & 0.167 & 0.000 & 0.026 & 0.000 & 0.000 & 0.125 & 0.056 & 0.000 & 0.059 & 0.000 & 0.000 & 0.000 & 0.000 & 0.074 & $\overline{0.070}$ & 2 \\
\hline 02. Politique commerciale & 375 & 0.500 & 0.083 & 0.000 & 0.077 & 0.179 & 0.083 & 0.071 & 0.000 & 0.054 & 079 & 0.000 & 0.100 & 000 & 0.000 & 0.000 & 0.029 & 0.000 & 0.000 & 0.000 & 0.000 & 0.057 & 0.078 & 4 \\
\hline 03. Politique économique & 0.133 & 0.083 & 0.067 & 0.100 & 0.118 & 0.048 & 0.156 & 0.057 & 0.000 & 0.029 & 0.039 & 0.037 & 0.027 & 0.000 & 0.026 & 0.013 & 0.012 & 0.000 & 0.000 & 0.000 & 0.003 & 0.044 & 0.045 & 15 \\
\hline 04. Travail & 0.250 & 0.000 & 0.100 & 0.500 & 0.096 & 0.071 & 0.000 & 0.000 & 0.083 & 0.054 & 0.013 & 0.111 & 0.000 & 0.000 & 0.014 & 0.000 & 0.000 & 0.000 & 0.000 & 0.000 & 0.000 & 0.040 & 0.062 & 4 \\
\hline 05. Assurances & 0.000 & 0.077 & 0.118 & 0.096 & 0.295 & 0.022 & 0.077 & 044 & 0.026 & 0.038 & .024 & 0.026 & 0.015 & 0.038 & 0.034 & 0.000 & 0.018 & 0.038 & 0.031 & 0.005 & 0.000 & .036 & 0.049 & 13 \\
\hline 06. Transport & 0.143 & 0.179 & 0.048 & 0.071 & 0.022 & 0.095 & 0.048 & 0.041 & 0.000 & 0.010 & 0.023 & 0.032 & 0.000 & 0.000 & 0.000 & 0.057 & 0.008 & 0.000 & 0.000 & 0.000 & 0.000 & 0.034 & 0.037 & 7 \\
\hline 07. Monétaire & 0.000 & 0.083 & 0.156 & 0.000 & 0.077 & 0.048 & 0.333 & 0.000 & 0.000 & 0.000 & 0.035 & 0.000 & 0.067 & 0.000 & 0.000 & 0.067 & 0.020 & 0.000 & 0.000 & 0.021 & 0.000 & 0.029 & 0.043 & 3 \\
\hline 08. Affaires étran & 0.143 & 0.071 & 0.057 & 0.000 & 0.044 & 041 & 0.000 & 0.048 & 0.000 & 0.020 & 0.045 & 0.016 & 0.000 & 0.000 & 0.016 & 0.000 & 0.008 & 0.048 & 0.000 & 0.000 & 0.034 & .027 & .028 & 7 \\
\hline 09. Citoyenneté & 0.167 & 0.000 & 0.000 & 0.083 & 0.026 & 0.000 & 0.000 & 0.000 & 0.335 & 0.048 & 0.018 & 0.037 & 0.000 & 0.000 & 0.000 & 0.067 & 0.000 & 0.000 & 0.000 & 0.021 & 0.000 & 0.023 & 0.038 & 3 \\
\hline 10. Divers & 0.000 & 0.054 & 0.029 & 0.054 & 0.038 & 0.010 & 0.000 & 0.020 & 0.048 & 0.022 & 0.011 & 0.016 & 0.043 & .054 & 0.024 & 0.014 & 0.004 & 0.000 & 0.014 & 0.000 & 0.010 & 0.022 & 0.022 & 14 \\
\hline 11. Science & 0.026 & 0.079 & 0.039 & 0.013 & 0.024 & 0.023 & 0.035 & 0.045 & 0.018 & 0.011 & 0.070 & 0.035 & 0.011 & 0.000 & 0.006 & 0.011 & 0.006 & 0.009 & 0.011 & 0.007 & 0.008 & 0.021 & 0.023 & 19 \\
\hline 12. Formation & 0.000 & 0.000 & 0.037 & 0.111 & 0.026 & 0.032 & 0.000 & 0.016 & 0.037 & 0.016 & 0.035 & 0.028 & 0.044 & 0.000 & 0.012 & 0.000 & 0.000 & 0.000 & 0.000 & 0.000 & 0.011 & .019 & .019 & 9 \\
\hline 13. Armée & 0.000 & 0.100 & 0.027 & 0.000 & 0.015 & 000 & 0.067 & 0.000 & 0.000 & +3 & 0.011 & 0.044 & 0.000 & 0.000 & 0.000 & 00 & 0.000 & 0.000 & 0.040 & 0.000 & 0.000 & .017 & 017 & 5 \\
\hline 14. Finances & 0.125 & 0.000 & 0.000 & 0.000 & 0.038 & 0.000 & 0.000 & 0.000 & 0.000 & 0.054 & 0.000 & 0.000 & 0.000 & 0.500 & 0.000 & 0.000 & 0.000 & 0.000 & 0.000 & 0.000 & 0.000 & 0.011 & 0.034 & 4 \\
\hline 15. Sanitaire & 0.056 & 0.000 & 0.026 & 0.014 & 0.034 & 0.000 & 0.000 & 0.016 & 0.000 & 0.024 & 0.006 & 0.012 & 0.000 & 0.000 & 0.052 & 0.000 & 0.003 & 0.019 & 0.022 & 0.000 & 0.000 & 0.012 & 0.014 & 18 \\
\hline 16. Communication & 0.000 & 0.000 & 0.013 & 0.000 & 0.000 & 0.057 & 0.067 & 0.000 & 0.067 & 0.014 & 0.011 & 0.000 & 0.000 & .000 & 0.000 & 0.100 & 0.000 & 0.000 & 0.000 & 0.013 & 0.000 & 0.012 & 0.016 & 5 \\
\hline 17. Agriculture & 0.059 & 0.029 & 0.012 & 0.000 & 0.018 & 0.008 & 0.020 & 0.008 & 0.000 & 0.004 & 0.006 & 0.000 & 0.000 & .000 & 0.003 & 0.000 & 0.000 & 0.000 & 0.000 & 0.004 & 0.003 & .009 & 008 & 17 \\
\hline 18. Environnement & 0.000 & 0.000 & 0.000 & 0.000 & 0.038 & 0.000 & 0.000 & 0.048 & 0.000 & 0.000 & 0.009 & 0.000 & 0.000 & 0.000 & 0.019 & 0.000 & 0.000 & 0.067 & 0.000 & 0.010 & 0.008 & .007 & 0.009 & 6 \\
\hline 19. Energie & 0.000 & 0.000 & 0.000 & 0.000 & 0.031 & 0.000 & 0.000 & 0.000 & 0.000 & 0.014 & 0.011 & 0.000 & 0.040 & 0.000 & 0.022 & 0.000 & 0.000 & 0.000 & 0.100 & 0.000 & 0.000 & 0.006 & 0.010 & 5 \\
\hline 20. Territoire & 0.000 & 0.000 & 0.000 & 0.000 & 0.005 & 0.000 & 0.021 & 0.000 & 0.021 & 0.000 & 0.007 & 0.000 & 0.000 & 0.000 & 0.000 & 0.013 & 0.004 & 0.010 & 0.000 & 0.017 & 0.000 & 0.004 & 0.005 & 16 \\
\hline 21. Culture & 0.000 & 0.000 & 0.003 & 0.000 & 0.000 & .000 & 0.000 & 0.034 & 0.000 & 0.010 & 0.008 & 0.011 & 0.000 & 0.000 & 0.000 & 0.000 & 0.003 & 0.008 & 0.000 & 0.000 & 0.033 & 0.004 & 0.005 & 21 \\
\hline $\bar{\varnothing}$ Inter & 0.074 & 0.057 & 0.044 & 0.040 & 0.036 & 0.034 & 0.029 & 0.027 & 0.023 & 0.022 & 0.021 & 0.019 & 0.017 & 0.011 & 0.012 & 0.012 & 0.009 & 0.007 & 0.006 & 0.004 & 0.004 & & & \\
\hline$\varnothing$ Gen & 0.070 & 0.078 & 0.045 & 0.062 & 0.049 & 0.037 & 0.043 & 0.028 & 0.038 & 0.022 & 0.023 & 0.019 & 0.017 & 0.034 & 0.014 & 0.016 & 0.008 & 0.009 & 0.010 & 0.005 & 0.005 & & & \\
\hline $\mathrm{N}$ & 2 & 4 & 15 & 4 & 13 & 7 & 3 & 7 & 3 & 14 & 19 & 9 & 5 & 1 & 18 & 5 & 17 & 6 & 5 & 16 & 21 & & & \\
\hline
\end{tabular}

Note : Probabilité de Variable homophily $=0.000(<0.05)$ : résultats significatifs ; Probabilité de Structural blockmodel $=0.000(<0.05)$ : résultats significatifs

\section{Annexe 5: Rang et valeurs des liens (nombre de membres en commun) des trois couples de commissions les plus exogames}

\begin{tabular}{|c|c|c|}
\hline Rang & Couples & Valeur \\
\hline 20 & Banque nationale suisse: Conseil de banque - Commission fédérale de la tuberculose & 1 \\
- & etc. & 1 \\
\hline- & & 1 \\
\hline
\end{tabular}

1957

\begin{tabular}{|c|c|c|}
\hline Rang & Couples & Valeur \\
\hline 4 & Comité consultatif pour les questions conjoncturelles - Commission consultative de la politique commerciale & 9 \\
6 & Comité consultatif pour les questions conjoncturelles - Commission fédérale d'experts pour l'introduction de l'assurance invalidité & 7 \\
13 & Commission d'experts pour une législation sur les cartels - Commission fédérale pour les questions intéressant le marché de l'emploi & 5 \\
\hline
\end{tabular}

\begin{tabular}{|c|c|c|}
\hline Rang & Couples & Valeur \\
\hline 2 & Commission consultative de la politique commerciale - Commission d'experts pour le tarif douanier et la limitation des importations & 8 \\
6 & Commission consultative de la politique commerciale - Commission pour la lutte contre les crises et la création demploi & 6 \\
\hline- & Commission consultative de la politique commerciale - Commission fédérale des possibilités de travail & 6 \\
\hline
\end{tabular}

2000

\begin{tabular}{|c|c|c|}
\hline Rang & Couples & Valeur \\
\hline 19 & Comité national suisse de la FAO - Commission pour les questions conjoncturelles & 3 \\
\hline- & Commission fédérale de la consommation - Conseil d'administration de la Caisse nationale suisse d'assurance en cas d'accident & 3 \\
\hline- & Commission consultative pour l'exécution de la loi sur l'agriculture - Commission consultative pour la politique économique extérieure & 3 \\
\hline
\end{tabular}




\section{Annexe 6 : Centralité de degré (Freeman) des 10 acteurs les plus centraux (réseau 2-core)}

\begin{tabular}{|l|l|c|}
\hline Nom & Affiliation & Degré \\
\hline Hunziker Hans & Administration fédérale & 9 \\
\hline Matter Erwin & Chemin de fer fédéraux (CFF) & 7 \\
\hline Kasser Paul & Tribunal fédéral & 6 \\
\hline Rohner Franz & Union syndicale suisse (USS) & 6 \\
\hline Muri Alois & PTT & 6 \\
\hline Bratschi Robert & Union syndicale suisse (USS) & 6 \\
\hline Müller Walter & Chemin de fer fédéraux (CFF) & 6 \\
\hline Oetiker Julius & Administration fédérale & 5 \\
\hline Meister Martin & Union syndicale suisse (USS) & 4 \\
\hline $\begin{array}{l}\text { Ringwald Fritz } \\
\text { Steiner Arthur } \\
\text { Schlumpf Jacques } \\
\text { Reichmann Franz } \\
\text { Cagianut Johann }\end{array}$ & Centralschweizerischen Kraftwerke & 4 \\
\hline & Union syndion des syndicale suisse (USS) & \\
\hline
\end{tabular}

\begin{tabular}{|l|l|c|}
\hline Nom & Affiliation & Degré \\
\hline Wyss Edmund & Union syndicale suisse (USS) & 37 \\
\hline Derron Leonhard & Union patronale suisse (UPS) & 36 \\
\hline Reichling-Oehninger Rudolf & Union suisse des paysans (USP) & 28 \\
\hline Jaggi Ernst & Union suisse des paysans (USP) & 28 \\
\hline Holzer Max & Administration fédérale & 26 \\
\hline Giroud Emile & Union syndicale suisse (USS) & 26 \\
\hline Geyer Ernst & Union suisse du Commerce et de I'Industrie (Vorort) & 24 \\
\hline Fink Manfred & Union suisse des arts et métiers & 24 \\
\hline Schaffner-Rudolf Hans & Administration fédérale & 23 \\
\hline Schmid-Ruedin Philipp & Schweizerischen Kaufmännischen Verein & 23 \\
\hline
\end{tabular}

1980

\begin{tabular}{|l|l|c|}
\hline Nom & Affiliation & Degré \\
\hline Juri René & Union suisse des paysans (USP) & 42 \\
\hline Hardmeier Benno & Union syndicale suisse (USS) & 42 \\
\hline Bonny Jean-Pierre & Administration fédérale & 39 \\
\hline Gruber Bruno & Confédération des syndicats chrétiens de Suisse (CSCS) & 38 \\
\hline Jolles Paul Rudolf & Administration fédérale & 32 \\
\hline Enggist Hans-Rudolf & Schweiz. Verbandes Technischer Betriebskader & 32 \\
\hline Barde-Martin Renaud & Syndicats patronaux romands & 28 \\
\hline Sauser-Im Obersteg Agnes & Association des Consommateurs & 27 \\
\hline Jucker Waldemar & Administration fédérale & 27 \\
\hline Allenspach-Wegelin Heinz & Union patronale suisse (UPS) & 25 \\
\hline
\end{tabular}

\section{0}

\begin{tabular}{|l|l|c|}
\hline Nom & Affiliation & Degré \\
\hline Gfeller Kurt & Union suisse des arts et métiers (USAM) & 17 \\
\hline Nova Colette & Union syndicale suisse (USS) & 12 \\
\hline Gaillard Serge & Union syndicale suisse (USS) & 11 \\
\hline Nordmann Jean-Luc & Administration fédérale & 11 \\
\hline Hasler Peter & Union patronale suisse (UPS) & 9 \\
\hline Stutz Vital & Association suisse des employés de la métallurgie & 9 \\
\hline Matthey Blaise & Syndicats patronaux romands & 8 \\
\hline Wisler Albrecht Annette & Confédération des syndicats chrétiens de Suisse (CSCS) & 8 \\
\hline Hartmann-Bertschi Regula & Confédération des syndicats chrétiens de Suisse (CSCS) & 8 \\
\hline $\begin{array}{l}\text { Daum Thomas } \\
\text { Schuppisser Hans Rudolf }\end{array}$ & $\begin{array}{l}\text { Association patronale suisse de l'industrie des machines (ASM) } \\
\text { Union patronale suisse (UPS) }\end{array}$ & 8 \\
\hline
\end{tabular}

Notes :

1. les représentant des associations d'intérêts sont surlignés en gris.

2. Nous n'avons pas inclus le tableau de 1910 pour des questions de place et car la centralité des acteurs y est faible et est donc peu significative. 
Annexe 7 : Centralité d'intermédiarité des 10 acteurs les plus centraux (réseau 2-core)

1937

\begin{tabular}{|l|l|c|}
\hline Nom & Affiliation & Intermédiarité \\
\hline Hunziker Hans & Administration fédérale & $3.70 \%$ \\
\hline Oetiker Julius & Administration fédérale & $2.11 \%$ \\
\hline Matter Erwin & Chemin de fer fédéraux (CFF) & $1.16 \%$ \\
\hline Ringwald Fritz & Centralschweizerischen Kraftwerke & $0.53 \%$ \\
\hline Fierz Robert & Administration fédérale & $0.21 \%$ \\
\hline Mutzner Karl & Administration fédérale & $0.11 \%$ \\
\hline Autres & Autres & $0.00 \%$ \\
\hline
\end{tabular}

1980

\begin{tabular}{|l|l|c|}
\hline Nom & Affiliation & Intermédiarité \\
\hline Bonny Jean-Pierre & Administration fédérale & $7.37 \%$ \\
\hline Hardmeier Benno & Union syndicale suisse (USS) & $5.91 \%$ \\
\hline Juri René & Union suisse des paysans (USP) & $5.39 \%$ \\
\hline Dubois Bernard & Administration fédérale & $5.09 \%$ \\
\hline Steiner Franz & Conseiller d'Etat du canton du Valais & $4.83 \%$ \\
\hline Jucker Waldemar & Administration fédérale & $4.41 \%$ \\
\hline Frei Xaver & Schweiz. Wirteverband & $4.40 \%$ \\
\hline Gruber Bruno & Confédération des syndicats chrétiens de Suisse (CSCS) & $3.59 \%$ \\
\hline Enggist Hans-Rudolf & Schweiz. Verbandes Technischer Betriebskader & $3.59 \%$ \\
\hline Schälchli Jakob & Schweiz. Strassenverkehrsverband & $2.91 \%$ \\
\hline
\end{tabular}

Notes :

1. les représentant des associations d'intérêts sont surlignés en gris.

2. Nous n'avons pas inclus le tableau de 1910 pour des questions de place et car la centralité des acteurs y est faible et est donc peu significative.
1957

\begin{tabular}{|l|l|c|}
\hline Nom & Affiliation & Intermédiarité \\
\hline Reichling-Oehninger Rudolf & Union suisse des paysans (USP) & $12.43 \%$ \\
\hline Derron Leonhard & Union patronale suisse (UPS) & $10.32 \%$ \\
\hline Hummler Fritz & Administration fédérale & $7.57 \%$ \\
\hline Geyer Ernst & Union suisse du Commerce et de I'Industrie (Vorort) & $7.11 \%$ \\
\hline Egger Viktor & USAM & $7.02 \%$ \\
\hline von Muralt Alexander & Université de Berne & $6.62 \%$ \\
\hline Wyss Edmund & Union syndicale suisse (USS) & $6.51 \%$ \\
\hline Derron Paul & Schweiz. Wirteverein & $5.62 \%$ \\
\hline Raaflaub Alfred & Schweiz. Strassenverkehrverband & $5.26 \%$ \\
\hline HessInOtto & Agriculteur, Parlementaire & $5.06 \%$ \\
\hline
\end{tabular}

2000

\begin{tabular}{|l|l|c|}
\hline Nom & Affiliation & Intermédiarité \\
\hline Daum Thomas & Association patronale suisse de l'industrie des machines (ASM) & $6.42 \%$ \\
\hline Nordmann Jean-Luc & Administration fédérale & $5.07 \%$ \\
\hline Gfeller Kurt & Union suisse des arts et métiers (USAM) & $4.91 \%$ \\
\hline Hasler Peter & Union patronale suisse (UPS) & $4.32 \%$ \\
\hline Gaillard Serge & Union syndicale suisse (USS) & $3.77 \%$ \\
\hline Nova Colette & Union syndicale suisse (USS) & $2.76 \%$ \\
\hline Hartmann-Bertschi Regula & Confédération des syndicats chrétiens de Suisse (CSCS) & $2.56 \%$ \\
\hline Stutz Vital & Association suisse des employés de la métallurgie & $1.29 \%$ \\
\hline Bravo-Baumann Heidi & Union suisse des paysans (USP) & $0.84 \%$ \\
\hline Schuppisser Hans Rudolf & Union patronale suisse (UPS) & $0.73 \%$ \\
\hline
\end{tabular}

